مقايسه ميزان ضايعات پس از برداشت ارقام روز كوتاه يیاز (Allium cepa L.)

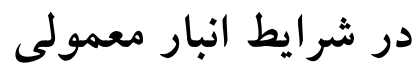

عبدالستار دارابى "

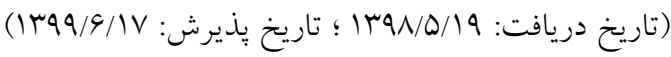

حكيده

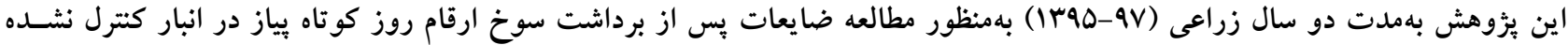

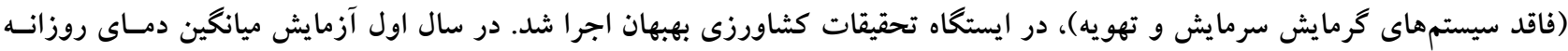

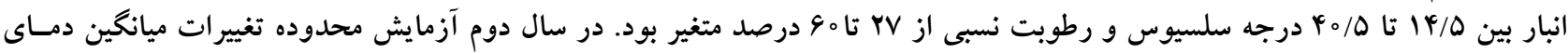

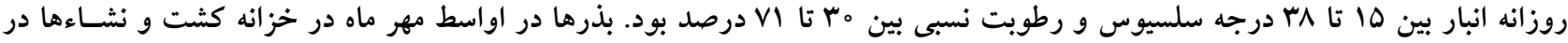

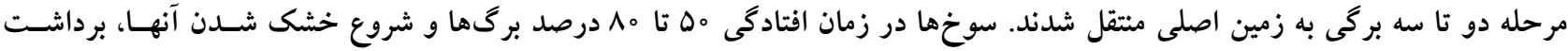

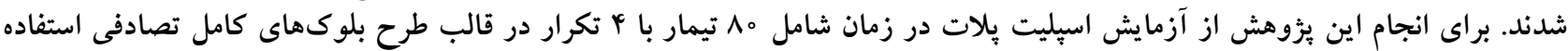

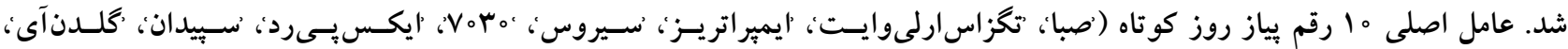

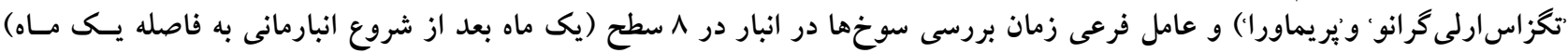

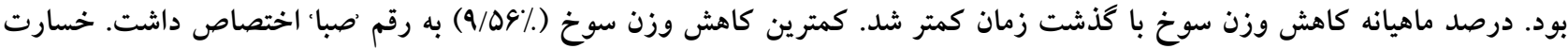

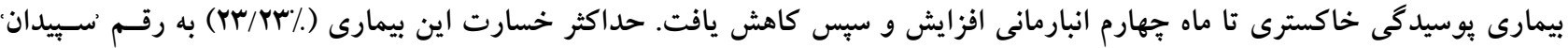

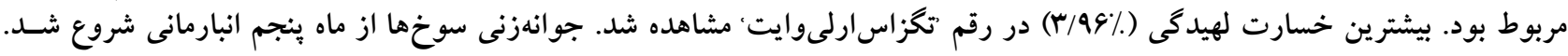

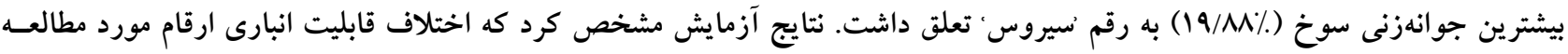

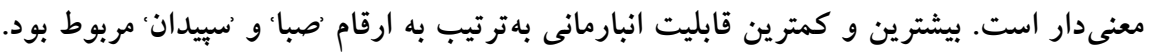

وازههاى كليدى: يوسيدگى خاكسترى، سبز شدن سوخ، ضايعات يس از برداشت، كاهش فيزيولوزيك وزن، لهيدگى سوخ

ا. دانشيار بخش تحقيقات اصلاح و تهيه نهال و بذر، مركز تحقيقات و آموزش كشاورزى و منابع طبيعى استان خوزستان، سازمان تحقيقـات، آمـوزش و

ترويج كشاورزى، اهواز، ايران.

* مسئول مكاتبات: يُت الكترونيكى: darabi6872@yahoo.com 
دليل بِايين بودن ماده خشك در مقايسه بـا ارقـام روز بلنـد، كـه

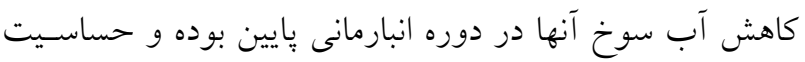

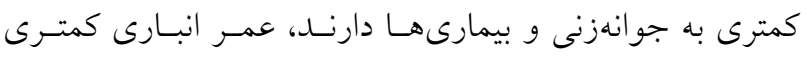
دارند (IV) ولى اختلاف معنى دار در قابليت انبارمانى بين ارقـام

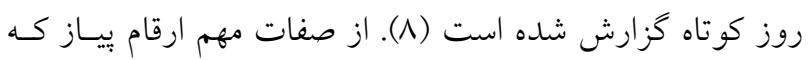

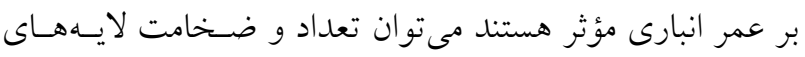

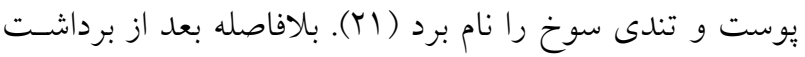

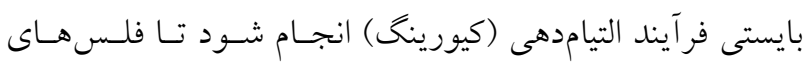
خارجى محكم و سفت شده، ميزان ترك يوست كـاهش يافتسه،

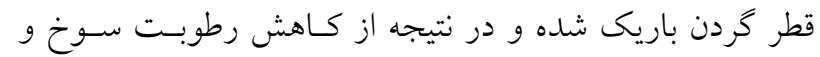

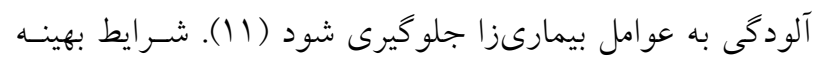
براى انبارمانى طولانى دماى ه تا ه درجه سلسـيوس و رطوبـت فئس

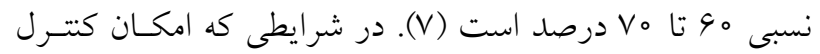
دما و رطوبت انبار وجود ندارد و يـا در منـاطق گـرم بـهمنظـور

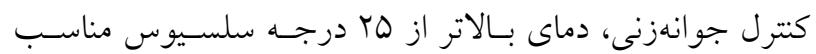

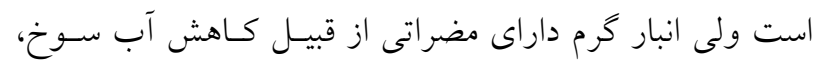

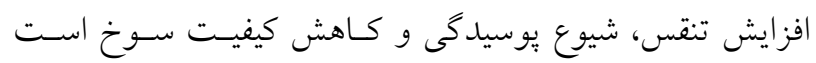

ميزان ضايعات بياز در انبار در اثر بيمارهاى پِّ از برداشت

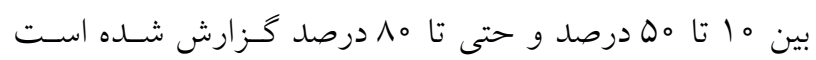

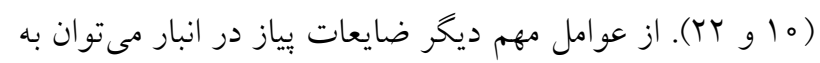

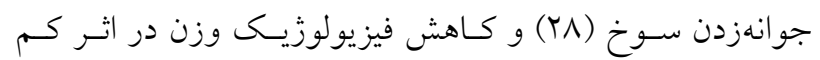
شدن آب، به دليل تعرق و تنفس، اشاره كرد (هو و 9).

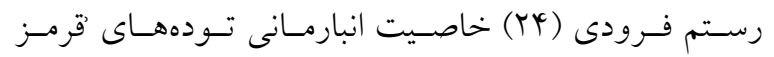

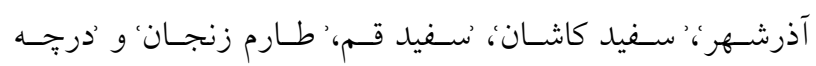

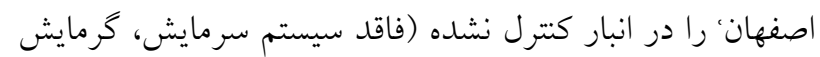

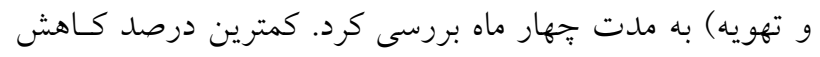

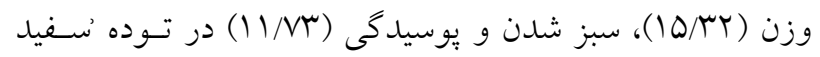

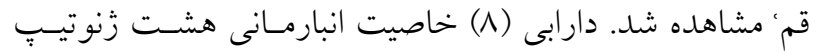

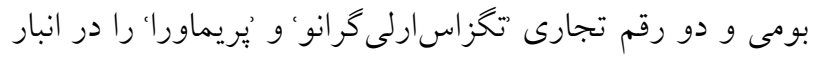

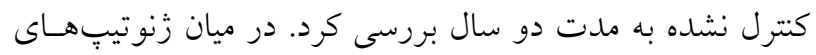
مورد مطالعه رقم "تخز اس ارلى گرانو و 'جمعيت بهبود يافتسه ييـاز

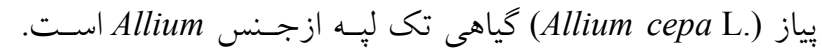
اين محصول بهدليل عطر و طعم و همجنين داشتن مقــدار قابـل

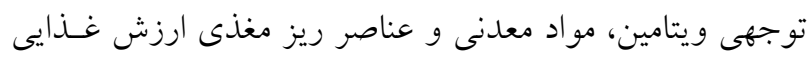

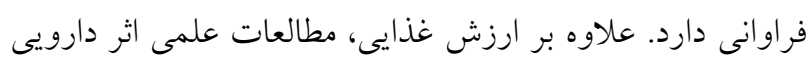

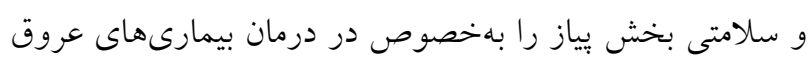

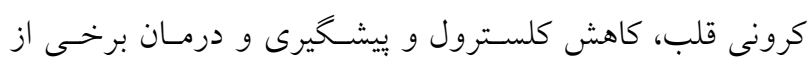

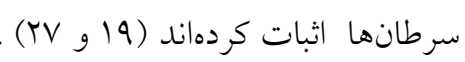
سوخ بياز يك اندام ذخيرهاى بوده و در نتيجه بياز براى انبار

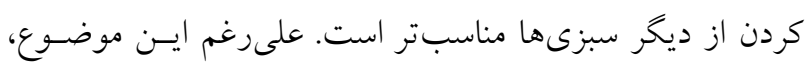
ميزان ضايعات يياز در مناطق گرمسيرى بالا است. انباردارى بياز

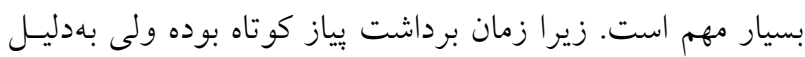

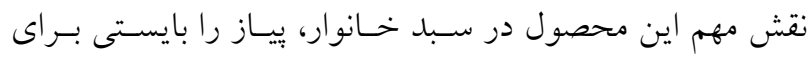

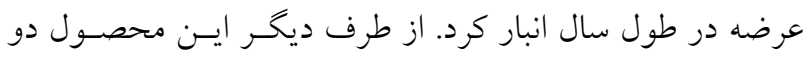

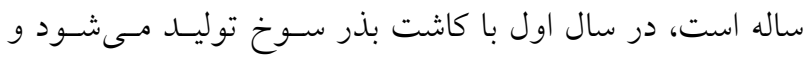

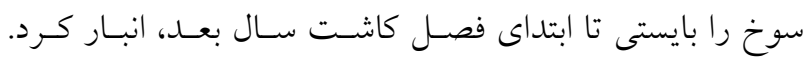

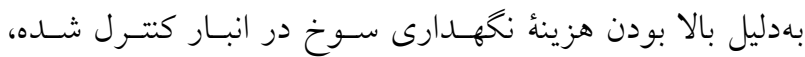
بلويزه در تابستان، تحقيقات زيادى در رابطه با بررسى انبارمانى

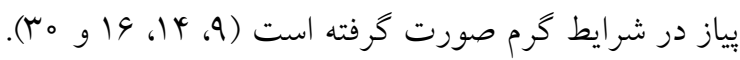

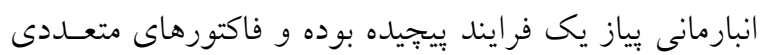

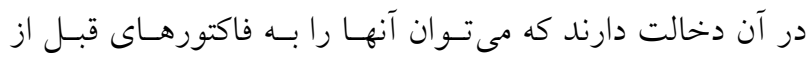

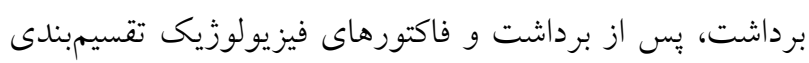

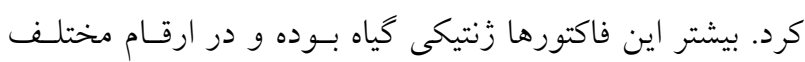
بسته به واكنش كياه به طول روز براى تشكيل سوخ (روز كوتاه،

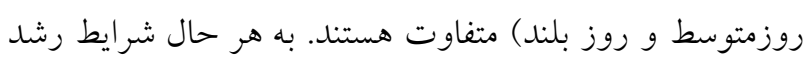

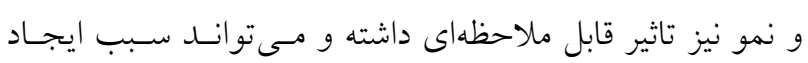

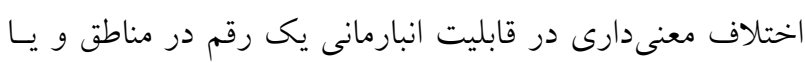

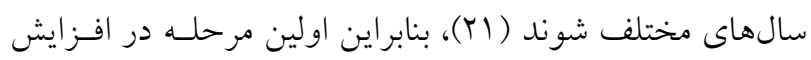

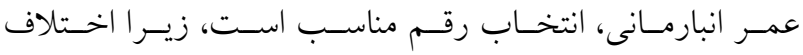

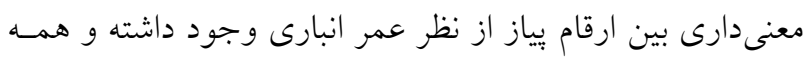

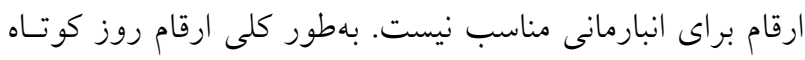

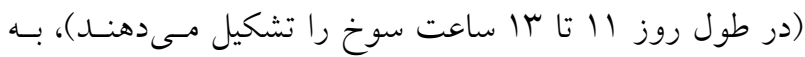


اواسط مهر ماه در خزانه كشت و نشـاءها در مرحلـه دو تـا سـه

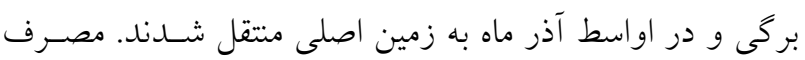
كود بر اساس نتايج آزمون خـاك و توصسيه موسسـه تحقيقـات

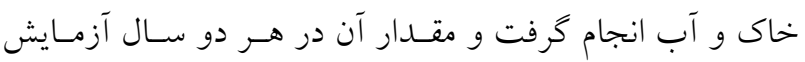
عبارت بود از 99 كيلو گرم P از منبع سوير فسفات تريبـل و

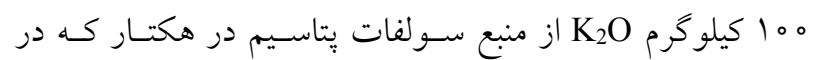

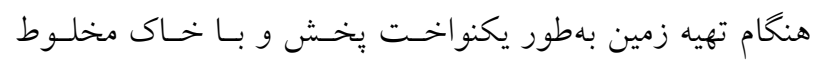
شدند. كود نيتروزنـه لازم نيـز بـهـ ميـزان هو كيلـو گرم نيتـروزن

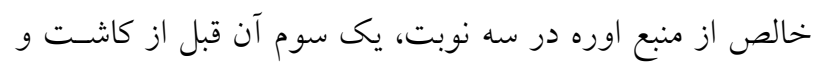
دو سوم بقيـه در دو نوبـت هأ روز بعـــ از نشـاءكارى و اوايـل سوخ دهى بهصورت سرك مصرف شد. آبيارى بهصورت نشـتى (جوى و بشته) و بر اساس نياز گياه انجـام گرفـت. طـول دوره يروش بسته به رقم حدود هشت مـاه تـا هشـت و نـيم مـاه (از اواسط مهر تا اواسط ارديبهشتـت و يـا اوايـل خـــداد مـاه) بـود.

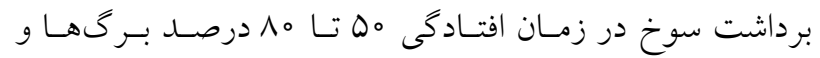
شروع خشك شدن آنها صورت گرفـت. از نظـر تقـويم زمـانى تاريخ برداشت سوخها بسته به رقم در سال اول آزمـايش از 19

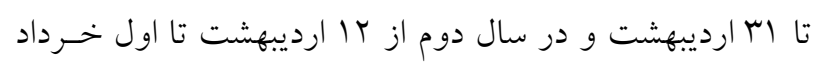

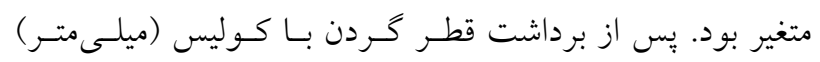

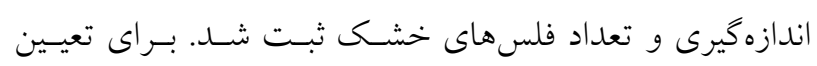
درصد ماده خشك سوخ، از هر كرت آزمايشى •ا سوخ بهطـور تصادفى انتخاب و يس از تميز و خرد كـردن، در آون در دمـاى 90 درجه سانتى گر اد بهمدت VY ساعت قـرارداده شـدند. بــراى اندازهكيرى مـواد جامــ محلـول كـل، ه السـوخ از هـر كـرت

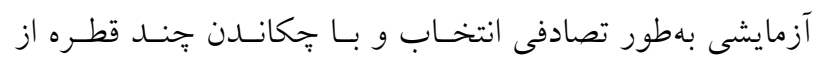
عصاره سوخ بر روى منشور دستخاه رفراكتـومتر ABBE مـدل

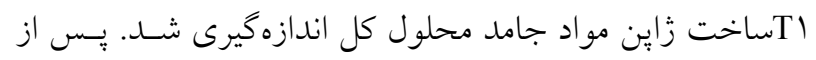
برداشت بهمنظور التيام دهى، سوخها بهملت دو هفته در مزرعـه

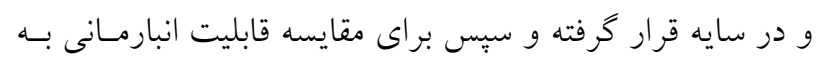
انبار كنترل نشده منتقل شدند. انبارمانى از اوايل خرداد شـروع و

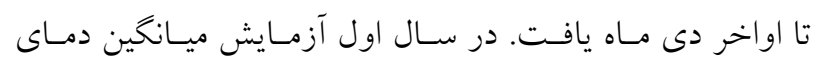

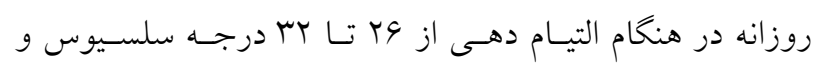

بهبهان" برترين زنوتيِّها بودند. كمـال و همكـاران (سا) دوازده رقم يبياز را در مقابل بيمارى بوسيدگى خاكسترى غربال كردنـــ.

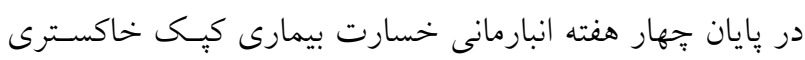
در رقم تتخزاسارلى وايت از ساير ارقـام كمتـر بـود و در همـــ ارقام شدت و ظهور بيمارى با افزايش دوره انبارمانى بيشتر شد.

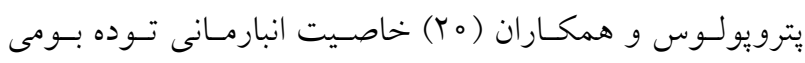
'واتى كيونيكو' و سه رقم 'سىوان، زد كروس' و 'كـريم گلـد' در دو دمـاى | ه كرد كه توده بومى 'واتى كيونيكو' را مىتوان بهمـــ V لمـاه و يـا بيشتر در دماى إذابرجهه سلسيوس نخهدارى كرد، در حالى كه در دماى إه درجه سلسيوس، اين زنوتيٍِ بدون كـاهش قابـل

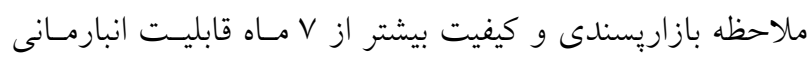
دارد. حدود هـه/ از سطح زير كشت بياز در كشور بـهـ اسـتانهـاى جنوبى اختصاص دارد (Y). علىرغم وجود تودههاى بومى متنسوع در جنوب كشور، بهدليل يايين بودن عملكرد اين تودههـا، در ايسن

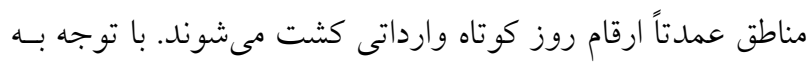
اينكه انبارمانى يكى از فاكتورهاى بسيار مهم در ارزيابى ارقام بيـاز است و تاكنون گزارشى در ارتباط با قابليت انبارمـانى ارقـام بيــاز روز كوتاه در كشور متشتر نشده اسـت، ايسن يـروهش بـهمنظـور مقايسه قابليت انبارمانى بيازهاى روز كوتاه در شرايط انبار كتتـرل نشده (فاقد سيستمهاى سرمايش، كرمايش و تهويه) انجام شد.

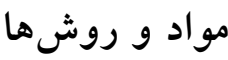

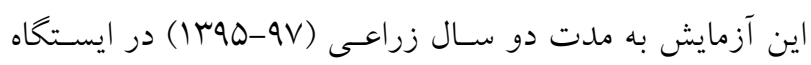
تحقيقات كشاورزى بهبهان واقع در 4 كيلـومترى شـرق بهبهـان

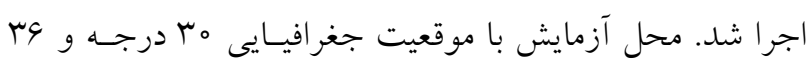
دقيقه عرض شـمالى و •ه درجـه و \& ا دقيقـه طـول شـرقى و ارتفاع هاب متر از سطح دريا و متوسط بارندكى وباب ميلى متـر داراى اقليم كرم و نيمه خشك است. براى اجراى ايسن آزمـايش بذرها (تهيه شده از شركت فلات ايران و خـل سـم كركـان) در 
=درصد كاهش فيزيولوزيك وزن

] [وزن سوخها در هر بررسى - وزن سوخها در ابتداى انبارمانى)

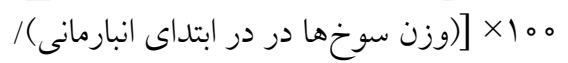

=درصد خسارت كيك خاكسترى =

وزن سوخهاى آلوده به كيكى خاكسـترى در هـر بررسـى )

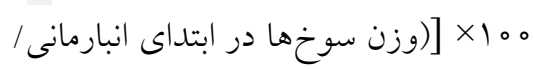

=درصد خسارت لهيدگى =

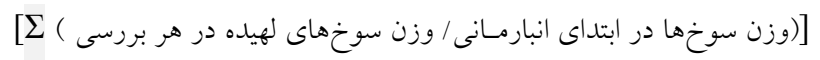
$\times 1$ 。

=درصد خسارت سبز شدن سوخ

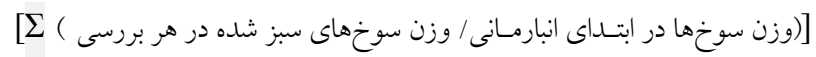
$\times 1 \circ \circ$

=درصد ضايعات كل =

] [وزن سوخها در ابتداى انبارمانى / وزن ضايعات كل در هر بررسى ) $\times 1 \circ \circ$

در پايان هر سال به كمك نـرمافـزار MSTATC بـراى صـفات ضايعات انبارى شامل درصد كـاهش فيزيولوزيــ وزن سـوخ، درصد سبز شدن سوخ، درصد سوخهاى لهيده و آلوده به كيكى خاكسترى و درصد ضايعات كل سـوخ و در سـال دوم درصـد مواد جامد محلول كل تجزيه واريانس ساده صورت كرفت. در يايان سال دوم تجزيه واريانس مركـب انجـام و ميـانخينهـا بـا استفاده از آزمون LSD در سطح احتمال ه درصد مقايسه شدند. علاوه براين، بر اساس ميزان تجمعى ضايعات كل بعد از سه ماه انبارمانى، ارقام در يكى از گروههاى زير قرار كرفتند:

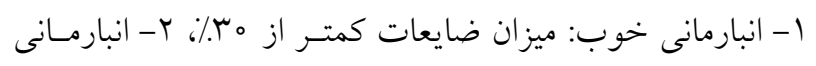
متوسط: ميزان ضايعات بين اس تـا هه.٪، ب- انبارمـانى ضـعيف:

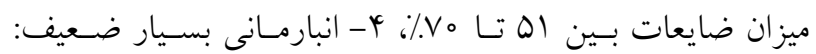

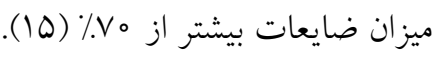

\section{نتايج و بحث}

نتايج تجزيه واريانس مشخص كرد كه اثر سال بر درصد كاهش
رطوبت نسبى از 9 تا TV درصد و در سـال دوم ميـانخين دمـاى روزانه از ه/ بr تا هr درجه سلسيوس و رطوبت نسبى از VIV

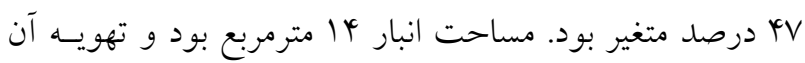
از طريق ينجره (بهطور طبيعى) صورت مسى گرفـت. انبـار فاقـــ سيستم سرمايش، گرمايش و تهويه بـود. در سـال اول آزمـايش

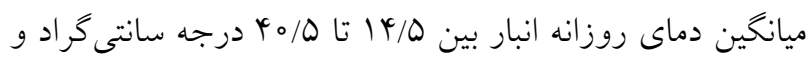

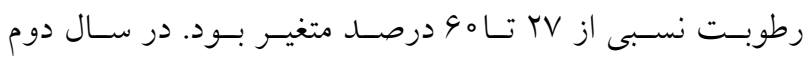

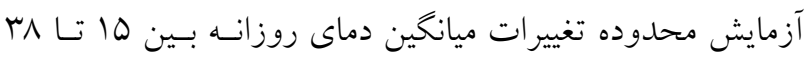

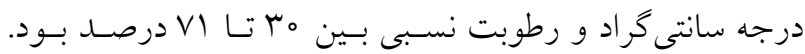

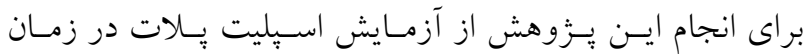

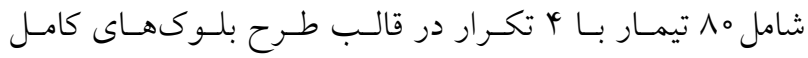
تصادفى استفاده شد. عامل اصلى ه ا رقم بياز روز كوتاه (ُصـبا،

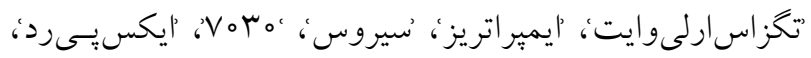

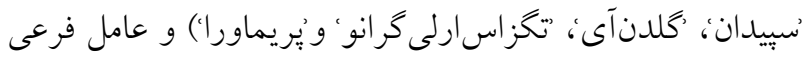
زمان بررسى سوخهـا در انبـار در ^ سـطح از يـك مـاه بعـــ از

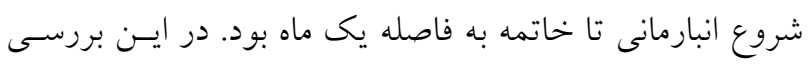

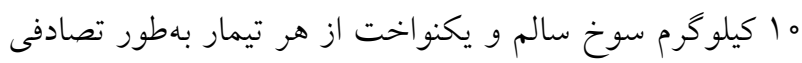

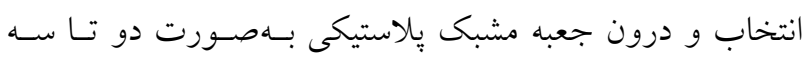
لايه، بسته به اندازه سوخ ارقام مورد مطالعـه، قـرار داده شــند. طول، عرض و ارتفاع جعبه بها بهترتيب •ه، r و و Y سانتى متـر بود. در انبار جعبهها بـهـ صـورت ثل رديـف روى هـم قـرار داده شدند و هر رديف به جعبههاى يك بلوك اختصاص يافتـ. در

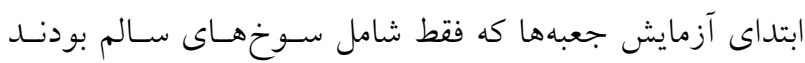

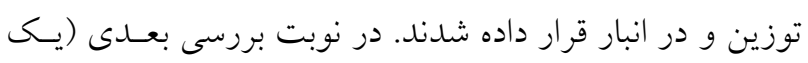
ماه بعد) جعبهها دو بار توزين شدند. در ابتـدا جعبـهــايى كـه. شامل سوخهاى سالم و سوخهاى آلوده به يوسيدگى خاكسترى، لهيده و جوانهزده بودند توزين شدند، بدين ترتيب ميزان كاهش وزن سوخهاى هر تيمار به صورت دقيق مشخص شد. در ادامـه

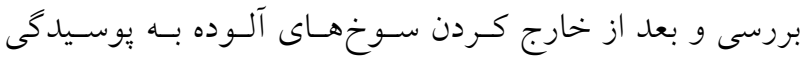
خاكسترى، لهيده و جوانهزده جعبـههـا دوبـار وزن شــند. ايسن روش تا انتهاى دوره انبارمانى ادامه داشت. ضايعات انبـارى بــه كمك روابط رير محاسبه شدند (r): 
جدول ا. نتايج تجزيه واريانس تجمعى درصد كاهش وزن سوخ، درصد يوسيدگى خاكسترى، درصد لهيدگى، درصد جوانهزنى و ضايعات كل

\begin{tabular}{|c|c|c|c|c|c|c|}
\hline \multicolumn{5}{|c|}{ ميانگين مربعات } & \multirow{2}{*}{ درجه آزادى } & \multirow{2}{*}{ منابع تغييرات } \\
\hline ضايعات كل & جوانهزنى & 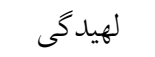 & يوسيدكى خاكسترى & كاهش وزن & & \\
\hline $1 \circ 0 \circ / \Pi V^{* *}$ & $r Q / Y^{*} \circ \Lambda^{* *}$ & $|\psi \circ / \Lambda|^{* * *}$ & $G \mu / \Lambda q Y^{\mathrm{nns}}$ & $\circ /$ M $q^{n s}$ & 1 & سال \\
\hline$\kappa r / \Delta \wedge \Delta$ &.$/ 191$ & $1 / T H A$ & $k+/ l<1$ & $r \mu / N V^{4}$ & 9 & تكرار در سال \\
\hline$|r| q / \mu q r^{* * *}$ & $\boldsymbol{\varphi} / \wedge \mid Q^{* *}$ & $V q / 4 q 1^{* *}$ & $\vee \wedge \Delta / Y ৭ 9^{* *}$ & $r V q / \circ \Delta q^{* *}$ & 9 & رقم \\
\hline GVN/GYQ** & $\Gamma / \Delta V Q^{* *}$ & $G Y / 4 \backslash 9^{* *}$ & $1 Y \Delta Q / 9 \circ \wedge^{* *}$ & $|r / \Lambda| 0^{* * *}$ & 9 & سال× رقم \\
\hline r०/VOS & $\circ / \circ V$ & $1 / 199$ & $\mathrm{r} / 90 \mathrm{~V}$ & IY/VOS & $\Delta Y$ & خطا (a) \\
\hline 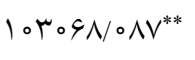 & 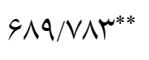 & $19 / 99)^{* * *}$ & $\Delta \Delta Q Y / \Delta V I^{* *}$ & MYMr/AKT*** & v & زمان انبارمانى \\
\hline $\mid Y V Y / \Delta G Y^{* *}$ & $৭ / \vee ৭ \Lambda^{* *}$ & 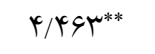 & $\Lambda Y / G M q^{* *}$ & G/Aץr** & v & سال× زمان انبارمانى \\
\hline FVI/OYI** & $r / q \uparrow Q^{* *}$ & $9 / 190^{* *}$ & $11 \circ \% \circ V^{* *}$ & $1 \circ / \Delta \wedge \Lambda^{* *}$ & q & رقم× زمان انبارمانى \\
\hline $199 / T r Q^{* *}$ & $1 / 190^{* *}$ & 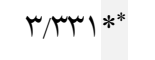 & $9 \circ / \mathrm{V} \circ 1^{* *}$ & 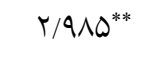 & rat & سال × رقم× زمان انبارمانى \\
\hline $9 / 9 \vee 0$ & $0 / 199$ & $\circ / 194$ & $r / \Delta \Delta 1$ & $1 / \mu Y D$ & YYo & خطا (b) \\
\hline
\end{tabular}

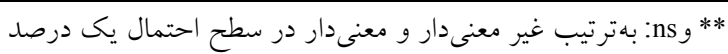

جدول r. رنگ بوست و مقايسه ميانگينهاى درصد كاهش وزن سوخ، درصد بوسيدگى خاكسترى، درصد لهيدگى، درصد جوانهزنى و ضايعات كل در ارقام مورد مطالعه

\begin{tabular}{|c|c|c|c|c|c|c|}
\hline ضايعات كل (٪) & جوانهزنى (.) & لهيدكى (\%) & يوسيدگى خاكسترى (.٪) & كاهش وزن (.) & رنخ يوست & رقم \\
\hline $\mathrm{rV} / 19^{\mathrm{g}}$ & $14 / 9 \circ d$ & $1 / 09 \mathrm{ef}$ & $|Y / 9|^{d}$ & $9 / 9 Q^{d}$ & زرد - مزد & صبا \\
\hline$(c q / 0)^{b c}$ & $19 / 1 Y^{c}$ & $r / 9 q^{a}$ & $\mid \psi / 4 \Delta^{c d}$ & $\mid Y / r \varphi^{b}$ & 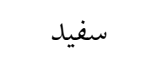 & تخزاس ارلى وايت \\
\hline KY/VYe & $1 \% / V \Delta^{c d}$ & $\circ / \Lambda r^{f}$ & $19 / 09 \mathrm{bc}$ & $11 / 10^{c}$ & 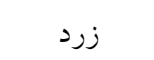 & ايمبر اتريز \\
\hline$\uparrow \wedge / V^{c}$ & $19 / 1 \Lambda^{\mathrm{a}}$ & $r / 9)^{b}$ & $1 \% / \circ 4 \mathrm{~cd}$ & $1 \% / \Delta \Delta^{b}$ & سفيد & سيروس \\
\hline$\uparrow \wedge / \Lambda \mu^{c}$ & $19 / 0 \mu^{\mathrm{bc}}$ & $T / \Psi \subset Q^{c}$ & $\mathrm{IV} / \circ \mathrm{rb}^{\mathrm{b}}$ & $1 \mu / \mu r^{b}$ & 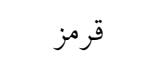 & $V \circ \mu_{0}$ \\
\hline$\mu \psi / \circ \wedge^{d}$ & $11 / 9 r^{\mathrm{e}}$ & I/rre & $|\mathrm{V} / \mathrm{A}|^{\mathrm{b}}$ & $|r /| r^{b}$ & 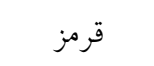 & ايكس يى رد \\
\hline$\Delta \psi / 9 \Lambda^{\mathrm{a}}$ & $\mid r / A V^{e}$ & $r / l Y^{c b}$ & 年 & $1 Q / V \varphi^{a}$ & سفبيد & سبيدان \\
\hline$Y V / M^{c}$ & $1 / / 9 r^{a}$ & $1 / \circ 9$ ef & $1 \% / \circ \mu^{c d}$ & $\mid r / \Lambda y^{b}$ & 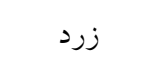 & كلدن آى \\
\hline$f \circ / \Lambda f^{f}$ & $19 / \circ \mathrm{V}^{\mathrm{bc}}$ & $1 / 0 y^{\mathrm{eef}}$ & $10 / 01^{e}$ & $\mid r / a Y^{b}$ & زرد & تخزاس ارلى گرانو \\
\hline $0 \circ / \Delta 9^{b}$ & $\mid Q / T \Delta^{c d}$ & $1 / 99^{d}$ & $19 / Y^{b \mathrm{bc}}$ & IV/०นa & يريماورا & يريماورا \\
\hline
\end{tabular}

ميانكينها با حروف مشترى در هر ستون از لحاظ آمارى اختلاف معنىدارى در سطح احتمال ينج درصد ندارند.

وزن سوخ معنى دار نبود. اثر رقم، اثـر متقابـل سـال و رقـم، اثـر ارقام مورد مطالعه يكسان نبود. حداقل كاهش وزن به رقم 'صـبا' زمان انبارمانى، اثر متقابل سال و زمان انبارمانى، اثر متقابـل رقـم مربوط بود و از لحاظ اين صفت اختلاف اين رقم با ساير ارقـام و زمان انبارمانى و اثر متقابل سال و رقم و زمان انبارمانى بر اين معنىدار بود (جــول r). تفـاوت در كـاهش فيزيولوزيـك وزن

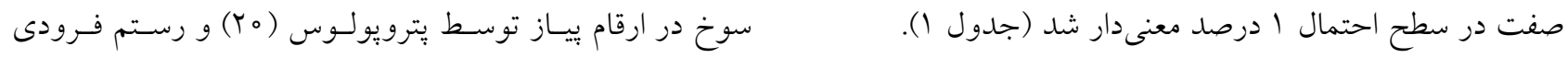

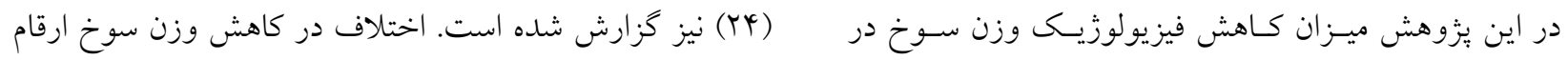




\begin{tabular}{|c|c|c|c|}
\hline درصد ماده خشك سوخ & قطر گردن (ميلىمتر) & تعداد يوست & 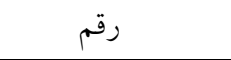 \\
\hline$V / 9 q^{c b c d}$ & $11 / \wedge_{0} a b$ & $r / 0 \circ^{a}$ & صبا \\
\hline$V / \circ q^{e}$ & $10 / \Delta \Lambda^{b c d}$ & $T / \Lambda \Lambda^{b c}$ & تخزاس ارلى وايت \\
\hline$V / r T^{d e}$ & 11/rسabc & $r / a \& b c$ & ايمير اتريز \\
\hline$V / \Gamma \Lambda^{\text {cde }}$ & $11 / \Delta \wedge^{\mathrm{abc}}$ & $r / 9 \circ b c$ & سيروس \\
\hline$q / \mu \varphi^{a}$ & $|Y / Y|^{a}$ & $r / \wedge \wedge^{\mathrm{ab}}$ & Vor。 \\
\hline$\Lambda / \mu I^{b}$ & $11 / 99 a b c$ & $\Gamma / \circ \wedge^{b c}$ & ايكس بيى رد \\
\hline$V / r Q^{\text {de }}$ & $\mid r / \mu_{\circ} a$ & $\mu / \circ \Delta^{b c}$ & 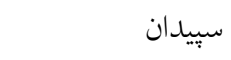 \\
\hline$V / Y r^{\mathrm{de}}$ & Q/VGd & $r / l \circ b c$ & كلدن آى \\
\hline$\Lambda / \Lambda Y^{b c}$ & $1 Y / 10^{a}$ & $r / V q^{c}$ & تخزاس ارلى گرانو \\
\hline $9 / 90 \mathrm{e}$ & $10 / 4 y^{\mathrm{cd}}$ & $r / \circ \circ b c$ & بريماورا \\
\hline
\end{tabular}

انبارمانى يكسان نبود. گر جهه بـا گذشـت زمـان درصــ كـاهش تجمعى وزن افـزايش يافـت (جـــول \&) ولـى رونـــ تغييـرات ماهيانه كاهش وزن سوخ با كذشت زمان نزولى بود (جدول ه).

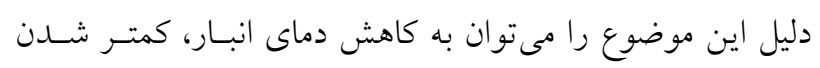
آب سوخ و بسته شدن كردن با كذشـت زمـان نسـبت داد (V).

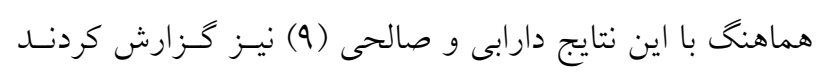
كه بيشترين كاهش وزن سوخ در اوايل دوره انبارمـانى مشـاهده شده اسـت. عليـرغم معنسى دار شــدن اتـــ متقابـل رقــم و زمـان

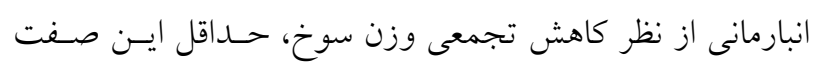
در سرتاسردوره انبارمانى به رقم 'صبا' مربوط بود (جدول 9).

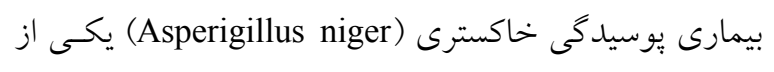
مخــبـتـرين بيمـارىهـاى بيـاز در دوره انبارمـانى در منـاطق

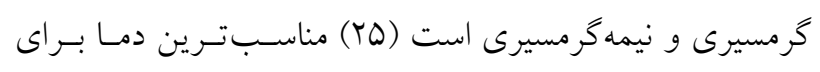

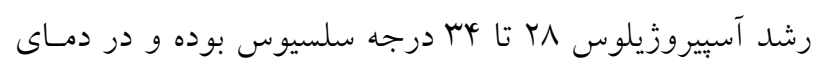
كمتر از V ل درجه سلسـيوس و بيشـتر از VV درجسهـ سلسـيوس

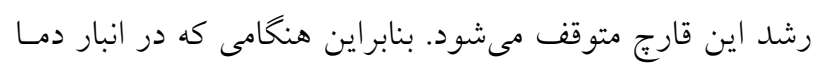

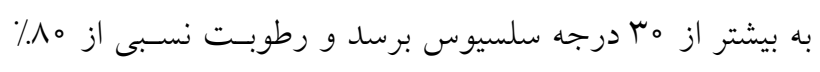
بيشتر شود اين بيمارى بـه شـدت شـايع مسىشـود (YY). نتسايج تجزيه واريانس نشان داد كه اثر رقم، اثر متقابل سال و رقم، اثـر
مختلف، ممكن است به دليل: ا- اخـتلاف در تعــاد و قابليـت نفوذ بذيرى بوست ب- اخـتلاف در قطـر و زمـان بسـته شـدن

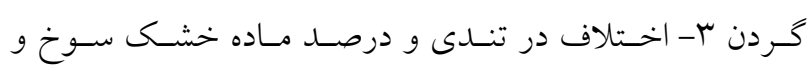
ץ- اختلاف در ضـخامت بوسـت باشــ (V) بــالا بــودن تعـداد يوست از دلايل مهم يـايين بـودن كـاهش فيزيولوزيـك وزن در

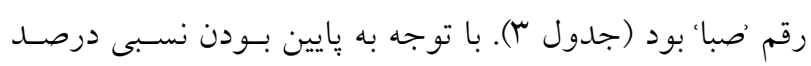
ماده خشك سوخ و بالا بودن نسبى قطر گردن اين رقم مىتـوان جنين نتيجه گيرى كرد كه نقـش تعـداد يوسـت در كـاهش وزن سوخ مهمتر از درصد ماده خشك سوخ و قطر گردن است. اين

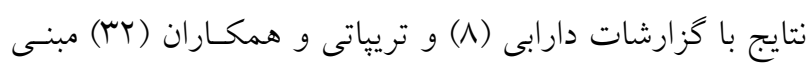
بر نقش مهم و تعيين كننده تعداد يوست در كاهش فيزيولوزيـك وزن مطابقت دارد. در اين يزوهش بيشترين كاهش وزن به رقـم 'يريماورا'، كه حاوى كمترين درصد مـاده خشـى سـوخ بـود و تعداد يوست آن نيز نسبتاً يايين بود، تعلق داشـت، از نظـر ايسن

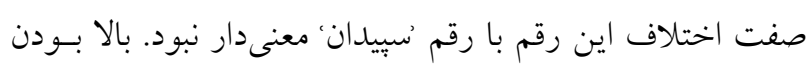
قطر كردن و يـايين بـودن نسـبى درصـد مـاده خشـى در رقـم 'سبيدان' سبب شد كه ميـزان كـاهش آب سـوخ در رقـم مزبـور نسبت به ساير ارقام افزايش معنىدارى را نشان دهد (جدول م).

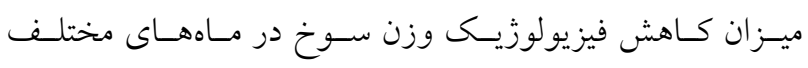


جدول f. مقايسه ميانگينهاى تجمعى درصد كاهش وزن سوخ، درصد بوسيدگى خاكسترى، درصد لهيدگى، درصد جوانهزنى و ضايعات كل در دوره انبارمانى

\begin{tabular}{|c|c|c|c|c|c|}
\hline ضايعات كل (.) & جوانهزنى (.) & لهيدگى (\%) & يوسيدگى خاكسترى (٪) & كاهش وزن (\%) & 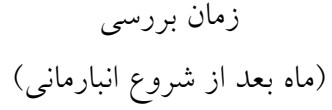 \\
\hline $4 / \circ \wedge^{h}$ & $\mathrm{oe}^{\mathrm{e}}$ & $\circ / q^{e}$ & $T / T V^{f}$ & $r / \Delta Y^{h}$ & اول \\
\hline $\mid r / \Lambda \circ g$ & $\circ \mathrm{e}$ & $0 / 99 \mathrm{~d}$ & $0 / 99 \mathrm{e}$ & $\varphi / 4 \Delta^{g}$ & دوم \\
\hline$r Y / \wedge q^{f}$ & $\circ \mathrm{e}$ & $1 / x+c$ & $1 \circ / \Delta V^{d}$ & $q / \wedge q^{f}$ & سوم \\
\hline$M / N V^{e}$ & $\circ \mathrm{e}$ & $r / 1^{b}$ & $19 \pi \Lambda^{c}$ & $\| / Y \Lambda^{e}$ & جهارم \\
\hline$\varphi \circ / \wedge q^{d}$ & $\circ / 9 \Delta^{d}$ & $r / v q^{a}$ & $r Y / \Delta r^{b}$ & $10 / 9 Y^{d}$ & ينجم \\
\hline$G 4 / V \Lambda^{c}$ & $r Y / r \Delta^{c}$ & $r / \Lambda r^{a}$ & $Y Y / q V^{a}$ & $\Lambda / \circ \mu^{d}$ & ششم \\
\hline $94 / 9 V^{b}$ & $\uparrow \wedge / \wedge^{b}$ & r/A & TY/VGa & $r \circ / r_{\circ} b$ & هفتم \\
\hline $100 / 00^{a}$ & $\Delta r / \Lambda \circ a$ & $r / \Lambda r^{\mathrm{a}}$ & Tr/VGa & $r \circ / 91^{a}$ & هشتم \\
\hline
\end{tabular}

جدول ه. مقايسه ميانگينهاى ماهيانه درصد كاهش وزن سوخ، درصد يوسيدگى خاكسترى، درصد لهيدگى، درصد جوانهزنى و ضايعات كل در دوره انبارمانى

\begin{tabular}{|c|c|c|c|c|c|}
\hline ضايعات كل (.) & جو انهزنى (.) & لهيدگى (.) & يوسيدگى خاكسترى (.) & كاهش وزن (\%) & (ماه بعد از شروع انبارمانى) \\
\hline $9 / \pi \Delta^{d}$ & $\circ$ & $\circ / \mu Y^{c}$ & T/TGd & $r / N V^{a}$ & اول \\
\hline $9 / 9 V^{d}$ & $\circ$ & $0 / T q^{c}$ & $r /\left.F\right|^{c}$ & $r / r V^{b}$ & دوم \\
\hline$\Lambda / V_{0} c$ & ${ }^{e}$ & $\circ / 99^{a}$ & $Y / \Lambda V^{b}$ & $r / l V^{b}$ & 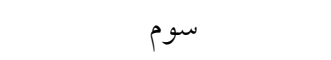 \\
\hline $9 / \pi r^{\mathrm{c}}$ & $\circ$ & $\circ / \Delta \mu^{b}$ & $\Delta / v q^{a}$ & $r / 9 I^{\mathrm{C}}$ & جهارم \\
\hline$N / 9 Y^{c}$ & $\circ / 9 \Delta^{d}$ & $\circ / 01^{b}$ & $Q / \circ \circ b$ & $r / r \& \mathrm{~d}$ & ينجم \\
\hline$Y Y / \mu_{\circ} \mathrm{c}$ & $r \circ / \mu \circ b$ & $\% \circ r^{d}$ & $1 / 0$ fe & $r / \mu r^{d}$ & ششم \\
\hline$r q / 1 \circ a$ & $T V / q^{\mu^{a}}$ & od & $\% / \% \mathrm{f}$ & $r / N \mu^{\mathrm{e}}$ & هفتم \\
\hline $\mathrm{Q} / 9)^{\mathrm{d}}$ & $\mathrm{Q} / \Delta \mathrm{S}^{\mathrm{a}}$ & $o^{d}$ & ${ }^{\circ} \mathrm{f}$ & $\circ /\left.4\right|^{f}$ & هشتم \\
\hline
\end{tabular}

ميانخينها با حروف مشترك در هر ستون از لحاظ آمارى اختلاف معنىدارى در سطح احتمال ينج درصد ندارند.

زمان انبارمانى، اثر متقابل سال و زمان انبارمانى، اثر متقابـل رقـم ز زنوتييى نسبت به اين بيمارى مصونيت نداشت. حسداقل درصــ

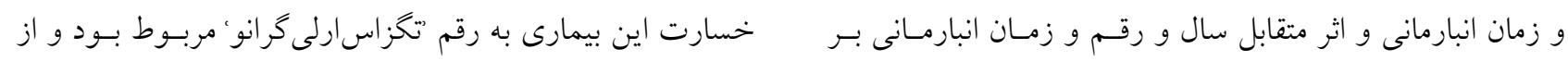

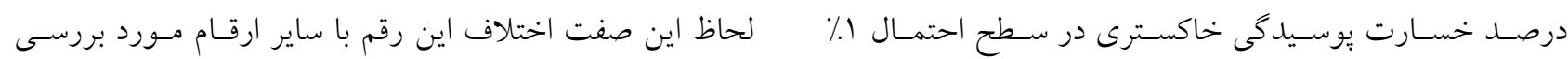

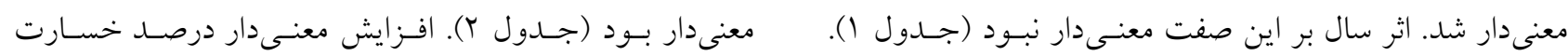

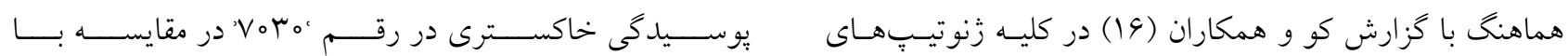

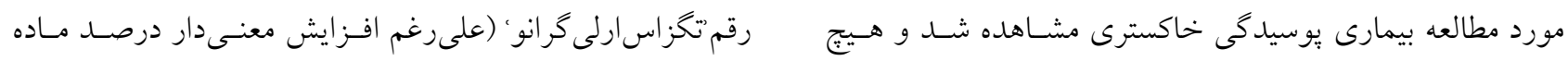


جدول و. مقايسه ميانكينهاى تجمعى اثر متقابل رقم و زمان انبار مانى بر درصد كاهش وزن سوخ، درصد بوسيدگى خاكسترى، درصد

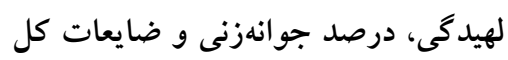

\begin{tabular}{|c|c|c|c|c|c|c|}
\hline ضايعات كل & جوانهزنى & لهيدكى & يو سيدكى خاكسترى & كاهش وزن سوخ & زمان بررسى & رقم \\
\hline & \multicolumn{3}{|c|}{ (درصد) } & \multicolumn{3}{|c|}{ (ماه بعد از شروع انبارمانى) } \\
\hline $9 / \wedge \wedge^{\mathrm{j} k 1}$ & $\circ Q$ & $\mathrm{o}^{\mathrm{T}}$ & $\Psi / \Psi \wedge \wedge^{Z a b}$ & $T / Y D^{c}$ & اول & \\
\hline $1 \% / 99^{\mathrm{efg} g}$ & $\circ Q$ & $\circ / \backslash^{\mathrm{LMNOP}}$ & $N / \notin q^{V}$ & $\varphi / \& q Y Z$ & دوم & \\
\hline $19 / \wedge r^{Z a}$ & $\circ Q$ & $1 / T V^{G H I J}$ & $11 / \wedge \circ \mathrm{ST}$ & G/VQW & سوم & \\
\hline$Y r / A V X Y$ & $\circ Q$ & $1 /$ TGGHI & $1 \% / \circ \wedge \mathrm{OPQR}$ & $N / F \mid U V$ & جهارم & صبا \\
\hline$r V / 4 \wedge V W$ & $\circ Q$ & $1 /$ $9 \mathrm{GHI}$ & $19 / 09 \mathrm{LMN}$ & $10 / 1 \mathrm{rST}^{\mathrm{ST}}$ & ينجم & \\
\hline$r q / 9 V^{P Q}$ & 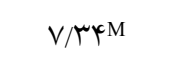 & $1 / \mathrm{TQGHI}^{-}$ & $19 / 09 \mathrm{LMN}$ & $11 / 9 \wedge^{\mathrm{PQ}}$ & ششم & \\
\hline$V V / \mu r F G$ & $\kappa r / N Y^{F G}$ & $1 / \Gamma q \mathrm{GHI}$ & $19 / 1 V^{\mathrm{LMN}}$ & $19 / 19^{1}$ & هفتم & \\
\hline $100 \% \mathrm{~A}$ & $9 \Delta / \Delta / \wedge^{A}$ & $1 / \mathrm{rGGH}^{\prime}$ & $19 / 1 V^{\mathrm{LMN}}$ & $19 / 99^{\mathrm{JKL}}$ & هشتم & \\
\hline $\mathrm{Y} / q_{\circ} \mathrm{kl}$ & ०Q & $\circ / / K^{T}$ & $1 / 1 \wedge^{\mathrm{ef}}$ & $r / \Upsilon^{\mathrm{abc}}$ & اول & \\
\hline$৭ / \Delta \Delta^{\text {hig }}$ & $\circ Q$ & $\circ / 9 V^{M N O P Q}$ & T/YYYde & $9 / 00^{W}$ & 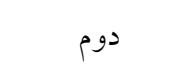 & \\
\hline $1 V / 9_{0} a b c$ & $\circ Q$ & $1 / \circ \wedge^{\mathrm{GHIJKLM}}$ & $9 / 4 \times X Y$ & $1 \circ / \wedge^{\mathrm{ST}}$ & سوم & \\
\hline$r \mid / l^{\mathrm{sT}}$ & $\circ Q$ & $F /\left.\mu\right|^{B C}$ & $\mid r / Y 4$ PRRS & $1 \% / 04 \mathrm{MN}$ & جهارم & تخزاس ارلى وايت \\
\hline$r \Delta / \Lambda r^{L M}$ & $\circ Q$ & $9 / T V^{A}$ & $Y Y / 4 \wedge$ CDEFG & $\mathrm{IV} / \circ \mathrm{V}^{\mathrm{JKL}}$ & لِنجم & \\
\hline$V Y / M^{E}$ & 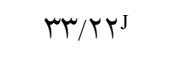 & $9 / \mathrm{rqA}$ & $r r / r \Lambda^{C D E}$ & $19 / 19^{\mathrm{EFGH}}$ & 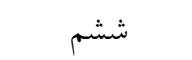 & \\
\hline $100 \% 0 \mathrm{~A}$ & YN/VG CDEFG & $9 / \pi q \mathrm{~A}$ & $r \Psi / Y \Lambda^{C D E}$ & $Y Y / \Delta \varphi \mathrm{CD}$ & هفتم & \\
\hline $100 \% \mathrm{~A}$ & $Y \wedge / V \varphi C D E F G$ & $9 / \mathrm{MqA}$ & $r r_{/ Y \Lambda^{C D E}}$ & $r Y / \Delta 9 C D$ & هشتم & \\
\hline $9 / 90^{\mathrm{jkl}}$ & $\circ Q$ & ו וPQRST & $\Gamma / \Lambda l^{a b c}$ & $r / \Lambda r^{\mathrm{bc}}$ & اول & \\
\hline $14 / \mu r$ def & $\circ Q$ & • $/ \Gamma^{\text {PQRST }}$ & $N / \mathcal{G N V}^{\mathrm{N}}$ & $\Delta / \sim_{Q X Y}$ & دوم & \\
\hline$r Y / \otimes V Y Z$ & $\circ Q$ & $\circ / \Gamma \backslash$ PQRST & $\left.|r /|\right|_{\text {QRS }}$ & $N / 1 Q^{U}$ & سوم & \\
\hline YN/GYTUVW & $\circ Q$ & o $/\left.\right|^{\text {PQRST }}$ & $|V / G| c L$ & $10 / 9 V^{R S}$ & جهارم & ايميراتريز \\
\hline$r \mathrm{r} / 9 \mathrm{VRS}$ & $\circ Q$ & $1 / \pi \Delta^{\mathrm{GHI}}$ & $19 / 9 Y^{J K}$ & $\mid r / \mu_{0} P$ & ينجم & \\
\hline$\Psi \mathrm{V} / \mathrm{T} \Delta^{\mathrm{KLI}}$ & $9 / N Y^{M}$ & $1 / \Gamma \Delta \mathrm{GHI}$ & YIN ${ }^{\mathrm{DEFGHI}}$ & $\mid \varphi / \kappa_{0} \mathrm{MN}$ & 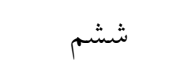 & \\
\hline$\wedge q / T \Delta^{C D}$ & $\nvdash q / \circ \nvdash E F G$ & $1 / r \Delta^{G H I}$ & $Y I / V \wedge^{\text {DEFGHI }}$ & $\mid \mathrm{V} / \wedge^{\mathrm{JKL}}$ & هفتم & \\
\hline $100 / 00 \mathrm{~A}$ & $\Delta Q / 0 / B C$ & $1 / \Gamma \Delta \mathrm{GHI}$ & $r I / V \wedge^{\text {DEFGHI }}$ & $\mathrm{IV} / \mathrm{G}_{\circ} \mathrm{IJ}$ & هشتم & \\
\hline $0 / 99^{\mathrm{kl}}$ & $\circ Q$ & $\circ / \pi \omega^{\mathrm{PQRST}}$ & $1 / \wedge r^{\mathrm{def}}$ & r/qrzab & اول & \\
\hline $11 / 19^{g h i}$ & $\circ Q$ & •/V入KLMNO & r/q ₹abc & 4/9\%W & دوم & \\
\hline $\mid V / T D^{a b c d}$ & $\circ Q$ & $T / Y T^{\mathrm{E}}$ & $9 / \mu^{X X Y Z}$ & $9 / \mu T^{\mathrm{TU}}$ & 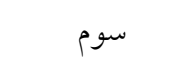 & \\
\hline TN/TAUVW & $\circ Q$ & $r / \wedge Q^{D}$ & $\mid r / r G \mathrm{RST}$ & $1 \% / 99 \mathrm{NO}$ & جهارم & سيروس \\
\hline$|Y / N|^{\mathrm{MN}}$ & $1 / \kappa^{\mathrm{P}}$ & $Y / Y V^{B C}$ & 19/9VIJK & $19 / 4 \circ \mathrm{KL}$ & لينجم & \\
\hline$\wedge \varphi / / \Lambda^{\mathrm{D}}$ & $\mu \psi / \wedge q^{H I}$ & $Y / Y V^{B C}$ & $r Y / 9 \varphi \mathrm{CDEFG}$ & $19 / \circ V^{G H}$ & 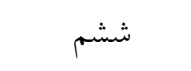 & \\
\hline $10 \% 00 \mathrm{~A}$ & $91 / \% 9 \mathrm{~A}$ & $Y / Y Y B C$ & $Y Y / 9 \varphi \mathrm{CDEFG}$ & $19 / \wedge \Delta^{\mathrm{EFGH}}$ & هنتم & \\
\hline $100 \% 0^{A}$ & $91 / \mathrm{TAA}^{\prime}$ & $Y / Y V^{B C}$ & $Y Y / 9 \varnothing \mathrm{CDEFG}$ & $19 / \wedge \Delta^{\mathrm{EFGH}}$ & هشتم & \\
\hline
\end{tabular}


ادامه جدول

\begin{tabular}{|c|c|c|c|c|c|c|}
\hline ضايعات كل & جوانهزنى & لهيدگى & يوسيدگى خاكسترى & كاهش وزن & زمان بررسى & رقم \\
\hline & \multicolumn{3}{|c|}{ (درصد) } & \multicolumn{3}{|c|}{ (ماه بعد از شروع انبارمانى) } \\
\hline$\Lambda / \Upsilon^{\mathrm{ijk}}$ & $\circ Q$ & $\circ / \Lambda$ YPQRST & $r / 9 q a b c$ & r/v GZab & 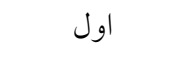 & \\
\hline $19 / \mu Y_{b c d e}$ & $\circ Q$ & $1 / / Y_{\text {GHIJKLM }}$ & N/rGVW & $\varphi / 4 \wedge W x$ & 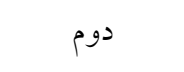 & \\
\hline rq/ITTUV & $\circ Q$ & $r / 9 \circ D$ & IQ/VYMNO & $10 / 495$ & سوم & \\
\hline rG/G PQPQ & $\circ Q$ & $r / 9 \circ D$ & YI/rVGHIJK & $1 \% / 9 V^{M N}$ & جهارم & $V \circ \mu_{0}$ \\
\hline$|q / 4|$ NO & $\circ Q$ & Y/QGD & r / $/ \Delta Q$ EFGHIJ & $\mid \mathcal{F} / \wedge \xi^{M}$ & ينجم & \\
\hline $09 / 9 Y^{I}$ & $M / Y^{L}$ & $T / 9 \varphi \mathrm{D}$ & YI/Q৭EFGHIJ & $\left.|V /|\right|^{\digamma J K L}$ & 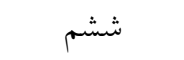 & \\
\hline $99 / T V^{A}$ & $\Delta Y / q \mu^{\mathrm{BCDE}}$ & $T / 9 \varphi^{\mathrm{D}}$ & r $/ 9$ Y DEFGH & $19 / V Y^{\mathrm{EFGH}}$ & هفتم & \\
\hline $100 \% \circ \mathrm{A}$ & $\Delta F / 99 B C D E$ & $r / 9 \& D$ & r $/ 9$ \&DEFGH & $r \circ / l^{E F G}$ & هشتم & \\
\hline $9 / \wedge \circ \mathrm{jkl}$ & $\circ Q$ & $\circ / \wedge^{\mathrm{ST}}$ & Y/VG bcde & $\Gamma / \Lambda Y^{Y Z a b}$ & 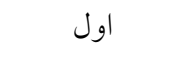 & \\
\hline $1 Q / \Delta Y^{c d e f}$ & $\circ Q$ & $\circ / 9$ FIJKLM & $V / q 4 V$ & $9 / 94 \mathrm{WW}$ & 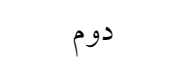 & \\
\hline$r V / 9 \circ \mathrm{VW}$ & $\circ Q$ & $1 / 4 \Delta \mathrm{GH}$ & $19 / \aleph^{\mathrm{LMN}}$ & $1 \% / 0 V^{S T}$ & سوم & \\
\hline$r Q / \& q Q R$ & $\circ Q$ & $1 / 4 Q^{\mathrm{GH}}$ & $r \mid / 4 I^{\text {FGHIJ }}$ & IT/GMOP & جهارم & ايكس بيى رد \\
\hline$r q / 1 \Gamma^{N O P}$ & $\circ Q$ & $1 / \uparrow \Delta^{\mathrm{GH}}$ & (Y & $1 \% / 09 \mathrm{MN}$ & ينجم & \\
\hline$Y Q / /\left.\right|^{\mathrm{KL}}$ & r/RNO & $1 / 4 Q^{\mathrm{GH}}$ & $r \mu / \Delta \Lambda^{C D}$ & $19 / 99 \mathrm{KL}$ & مشم & \\
\hline$\Lambda \Upsilon / \Lambda \Delta^{E}$ & $\mathrm{rV} / 9)^{\mathrm{J}}$ & $1 / \Psi^{\oplus G \mathrm{GH}}$ & $r \mu / \Delta \Lambda^{C D}$ & $19 / 94 \mathrm{FGH}$ & هفتم & \\
\hline $100 / 00 \mathrm{~A}$ & $\Delta \% / \circ Y^{B C D E}$ & $1 / 4 Q^{\mathrm{GH}}$ & $\mathrm{r} / \mathrm{O \Lambda} \mathrm{CD}$ & $19 / 99 \mathrm{EF}$ & هشتم & \\
\hline$\Delta / ৭ \wedge^{\mathrm{kl}}$ & $\circ Q$ & ${ }^{\mathrm{T}}$ & $1 / 09$ ef & $\uparrow / \mu q Y Z a$ & اول & \\
\hline $\mid r / \mu \wedge^{\mathrm{fgh}}$ & $\circ Q$ & $\circ / 9 \wedge^{\mathrm{IJKLM}}$ & $y / I^{Y Z a}$ & $9 / 99^{W}$ & 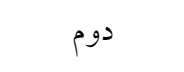 & \\
\hline $19 / 94 \mathrm{Za}$ & $\circ Q$ & 1/94EF & V/A rVWX & $1 \circ / \bigwedge \wedge^{\mathrm{ST}}$ & 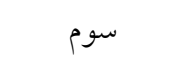 & \\
\hline$r q / \wedge \mu^{N O P}$ & $\circ Q$ & $r / 9 \circ \mathrm{C}$ & $19 / \Delta \Delta^{K}$ & $19 / \mu \wedge^{\mathrm{KL}}$ & جهارم & سيدان \\
\hline$G \mathcal{Y} / \Delta \Lambda^{\mathrm{H}}$ & r/4YN & $\varphi / \mu v^{B}$ & re/M4B & ror س & ينجم & \\
\hline $91 / \wedge Y^{C}$ & $r q / \mu \mathrm{K}$ & $y / G Y^{B}$ & $\Gamma \wedge / \Delta \wedge^{A}$ & $T Y / T I^{B C}$ & ششم & \\
\hline $100 / 00 \mathrm{~A}$ & $M / Q Y^{I J}$ & $Y / G Y B$ & $r N / Q \Lambda^{A}$ & $T Y / \wedge \mathcal{G}^{B}$ & هفتم & \\
\hline $100 / 0 \circ \mathrm{A}$ & MT/QYIJ & $y / 94 B$ & $\Upsilon \wedge / \Delta \wedge^{A}$ & $r Y / \wedge \varphi^{B}$ & هشتم & \\
\hline $4 / 90^{1}$ & $\circ Q$ & $\circ / 11 \mathrm{STU}$ & 1/Mref & $r / \uparrow \& Z a b c$ & اول & \\
\hline 1०/^rghi & $\circ Q$ & $\circ /$ YYQRST & $r / 9 \Lambda^{\text {abcd }}$ & $9 / 91 \mathrm{~W}$ & دوم & \\
\hline TI/99YZ & $\circ Q$ & ०/৭१ IJKLMN & $Q / \Delta$ YUV & $11 / 1 \mu^{Q R S}$ & سوم & \\
\hline${ }^{\mathrm{W}} / / \wedge^{\mathrm{STU}}$ & $\circ Q$ & $|/|^{\mathrm{GHIJ}}$ & $1 Q / V 4$ MNO & $\mid \psi / / \mu^{M N}$ & جهارم & كَلدن آى \\
\hline rV/VQOPQ & $\circ Q$ & $1 / 4 \varphi^{\mathrm{GH}}$ & $Y_{\circ} / / Y^{J K}$ & $19 / T_{0} \mathrm{~L}$ & ينجم & \\
\hline VN/צ̆ $\mathrm{EF}$ & $\mathrm{rV} / 99 \mathrm{IJ}$ & $1 / 49 \mathrm{GH}$ & Y०/91 HIJK & / $/ / q^{\circ} \mathrm{HI}$ & ششم & \\
\hline $100 / 00 \mathrm{~A}$ & $\Delta V / A Y B C$ & $1 / 44 \mathrm{GH}$ & Y०/9| HIJK & $19 / 99^{\mathrm{EFGH}}$ & هفتم & \\
\hline $100 / 00 \mathrm{~A}$ & $\Delta V / q Y B C$ & $1 / 44 \mathrm{GH}$ & $r_{\circ} /\left.9\right|^{\mathrm{HIJK}}$ & $19 / 99 \mathrm{EFGH}$ & هشتم & \\
\hline
\end{tabular}




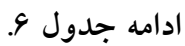

\begin{tabular}{|c|c|c|c|c|c|c|}
\hline ضايعات كل & جوانهزنى & لزهيد & يوسيدكى خاكسترى & كاهش وزن & زمان بررسى & رقم \\
\hline & \multicolumn{3}{|c|}{ (درصد) } & \multicolumn{3}{|c|}{ (ماه بعد از شروع انبارمانى) } \\
\hline$\varphi / \circ \varphi_{j \mathrm{jkl}}$ & $\circ Q$ & ${ }^{\mathrm{T} T}$ & $\circ / \mu Y \lambda^{e f}$ & $r / v Y_{Z a b}$ & اول & \\
\hline $1 \circ / \wedge V_{\text {ghi }}$ & $\circ Q$ & $\circ / \Upsilon^{\mathrm{RST}}$ & $Y / M \wedge_{Z a b}$ & $q / r q w x$ & دوم & \\
\hline $19 / 99 \mathrm{bcd}$ & $\circ Q$ & $\circ / 9$ YIJKLMN & g/9 rwx & $9 / 1)^{\mathrm{TUV}}$ & سوم & \\
\hline$r r / 99 X Y$ & $\circ Q$ & I/THIJ & $1 \circ / \mathrm{V}^{\mathrm{TU}}$ & $11 / 99 \mathrm{PQR}$ & جهارم & تخز اسارلى گرانو \\
\hline rی/৭rSTU & $\circ Q$ & $1 / \uparrow q F G$ & $1 Y / 9 M_{Q R S}$ & $|Y / D|^{M N}$ & ينجم & \\
\hline $0 \circ / q^{J K L}$ & $19 / 09 L$ & $1 / 4 q F G$ & $1 \% / N Q^{M N O P Q}$ & IV/4夭 JJ & 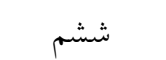 & \\
\hline $91 / 4 \circ \mathrm{CD}$ & $\Delta Y / V \Delta^{B C D}$ & $1 / \uparrow q^{F G}$ & $10 / 1 \mu^{N O P}$ & $r \circ / \bigwedge^{\mathrm{EFG}}$ & هفتم & \\
\hline $100 \% 0 \mathrm{~A}$ & $G Y / M^{A}$ & $1 / \uparrow q F G$ & $10 / 1 \mu^{N O P}$ & $r_{\circ / 4 q D E F}$ & 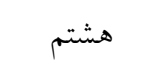 & \\
\hline$q / Y q k 1$ & $\circ Q$ & $\circ / 9 Y^{N O P Q R}$ & $1 / N \mu_{e f}$ & $r / q$ Yab & اول & \\
\hline $1 \% / \Delta q^{e f g}$ & $\circ Q$ & $\circ / 9 Y^{N O P Q R}$ & $Y / D \circ Z a b$ & $\Lambda / \mathcal{F V U V}$ & دوم & \\
\hline$r \varphi / \Lambda / W X$ & $\circ Q$ & $1 / 19 \mathrm{GHIJK}$ & $11 / 9 \wedge^{\mathrm{ST}}$ & $\mid r / q 4$ NO & سوم & \\
\hline$r q / \circ Q Q R$ & $\circ Q$ & $1 /\left.\Delta\right|^{\mathrm{FG}}$ & $\mid V / \Psi_{0} L M$ & $I V / \backslash \Lambda^{J K L}$ & جهارم & يريماورا \\
\hline$\ll q / \wedge V^{K}$ & Y/q & $r / \circ \circ D$ & $r Y / \Delta r^{C D E F}$ & $19 / V^{E F G H}$ & ينجم & \\
\hline$V \Psi / Q 9 G$ & $r \Phi / 11^{K}$ & $r / \circ \circ D$ & $r \Pi / M^{C}$ & $T Y / 9 \circ B C$ & ششم & \\
\hline $99 / 4 \mu^{B}$ & $Y Y / D \circ G H$ & r/O०D & $r / \Lambda^{C}$ & $r Y / \circ D^{A}$ & هفتم & \\
\hline $100 / 00 \mathrm{~A}$ & $\uparrow \vee / 4 \wedge C D E F$ & r/O०D & $r / \Lambda^{C}$ & $r Q / G Y A$ & هشتم & \\
\hline
\end{tabular}

ميانكينها با حروف مشترك در هر ستون از لحاظ آمارى اختلاف معنى دارى در سطح احتمال ينج درصد ندارندا.

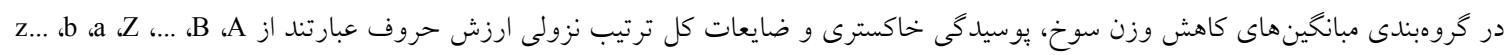

Y). هماهنخ با اين نتايج كو و همكاران (19) نيز گزارش كردند ارتبـاطى بــين رنــ سـوخ و خسـارت ايسن بيمـارى مشـاهده نكرداند. برخلاف اين نتـايج كمـال و همكـاران (با) خـزارش

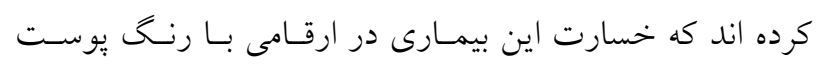
سفيد كمتر است. بررسى روند تغييـرات خسـارت ماهيانـه ايسن بيمارى در دوره انبارمانى نشان داد كه تـا ل مـاه بعـد از شـروع انبارمانى (شهريور ماه) درصــ خسـارت ايسن بيمـارى افـزايش يافت و سيس از شدت آن كاسـته شـد (جـــول ه). دليـل ايـن موضوع را مىتوان به كاهش دماى انبار از مـاه يـنجم انبارمـانى (مهر ماه) نسبت داد. اين نتايج با گزارش تـاىسـونى و فـولرتن

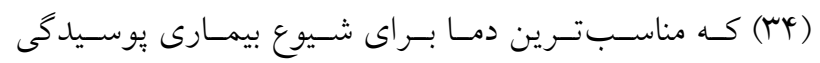

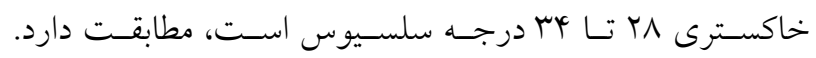

خشك اين رقم نسبت به رقم 'تخزاسارلى گرانو،) همان كونه كه توسط كو و همكاران (91) گزارش شده نشاندهنده اين مطلـب است كه علاوه بر درصد ماده خشك سـوخ، عوامـل ديخـرى از جمله خصوصيات زنتيكى نيز در مقاومت به بيمارى بوسـيدگى خاكسترى مؤثرند. دارابى (N) نيز در بررسىهاى خود بـا جنـين موضوعى مواجه شد و نتيجه گيرى كردند كـه ارتبـاط بـين ايسن

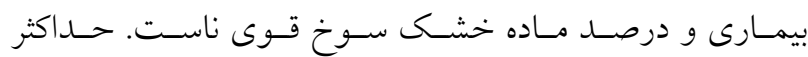
خسارت اين بيمارى در رقم نسيدان' (بـا رنــ بوسـت سـفيد) مشاهده شد. هر جنـد كاهش خسارت ساير ارقام مـورد مطالعـه در مقايسه با اين رقم معنسىدار بـود ولـى ميـزان خسـارت ايسن بيمارى در ارقامى با رنخ يوست زرد ('بريماورا' و 'يمبراتريسز، )

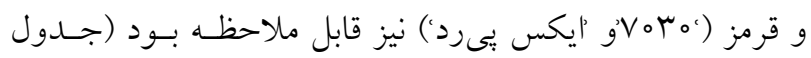


بر خلاف ايسن گزارشـات در ايـن يـزوهش كمتـرين خسـارت

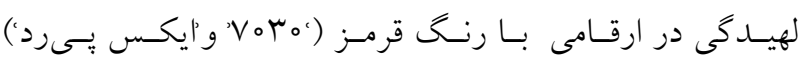
مشاهده نشد (جدول Y) كه منعكس كننده اين مطلب اسـت كـه

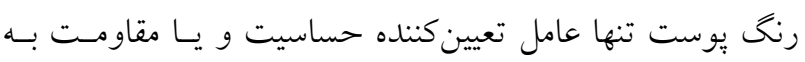

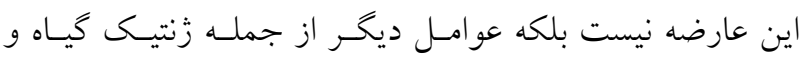

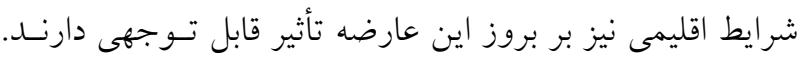

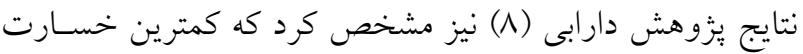

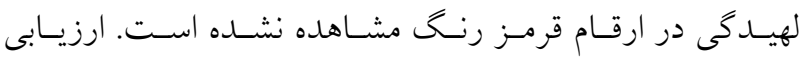
خسارت ماهيانه درصد لهيدكى مشخص كرد كـه تـا مـاه سـوم (مرداد ماه) انبارمانى روند تغييرات درصد خسارت اين عارضسه صعودى بود ولى از ماه جهارم انبارمانى (شهريور مـاه) بـهدليـل

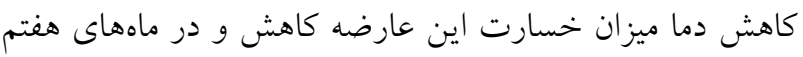
و هشتم انبارمانى (آذر و دى) خسارت اين عارضه متوقف شـــ

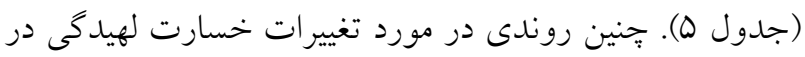

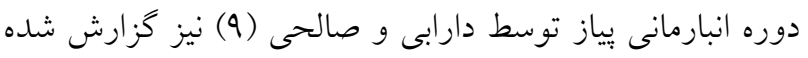

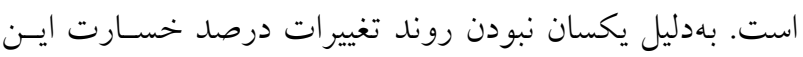

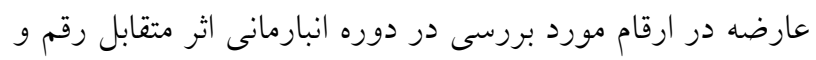

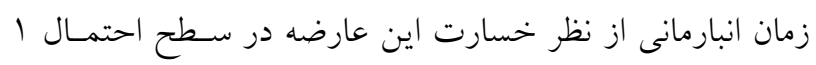
درصد معنى دار شد (جدول 9).

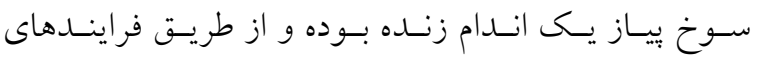

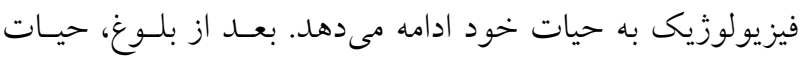

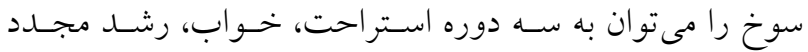
(جوانهزنى) تقسيمبندى كرد. در دوره اسـتراحت كـه بلافاصـله

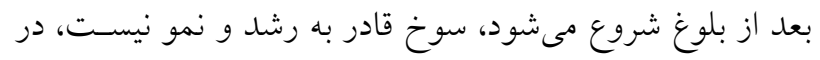

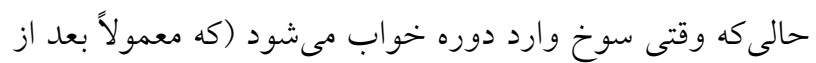

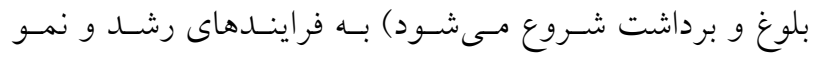

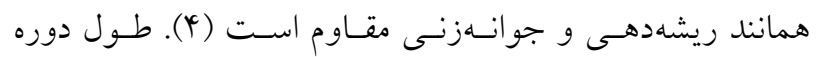
خواب به رقم، مرحله برداشت، شرايط رشــ و نمـو در مزرعـهـ

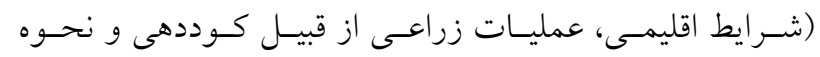

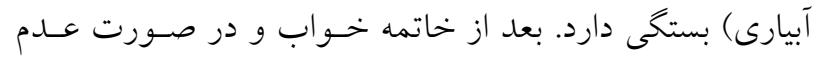

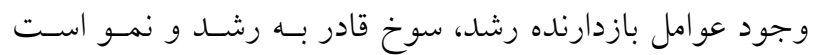

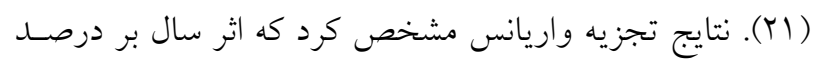

كـاهش درصـد خسـارت ايـن بيمـارى بـا كـاهش دمـا توسط

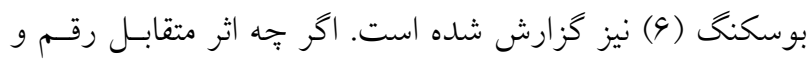

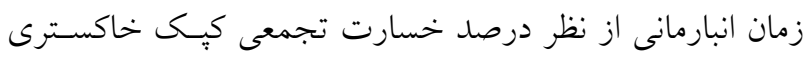

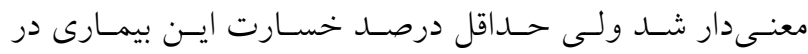

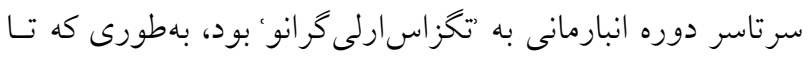

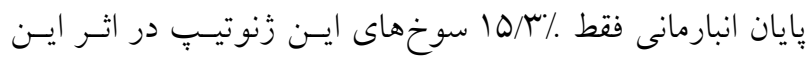

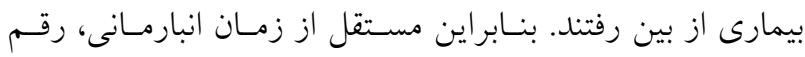

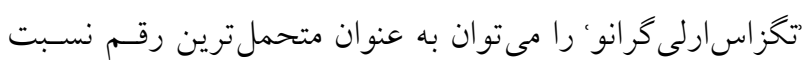
به اين بيمارى معرفى كرد. (جدول 9).

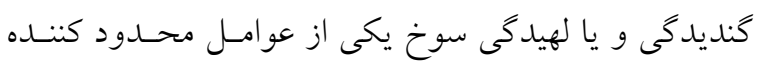

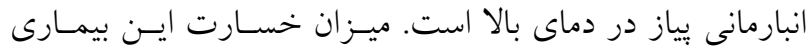

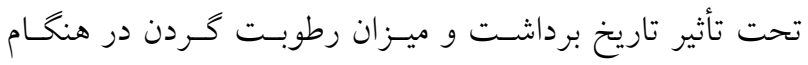
برداشت متغير است (צY). درصد خسـارت ايـن بيمـارى در دو

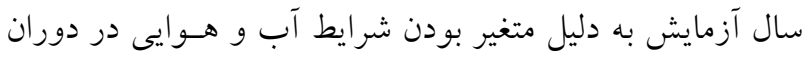

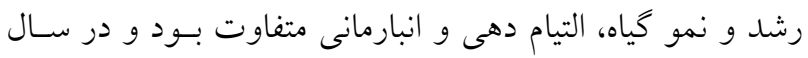

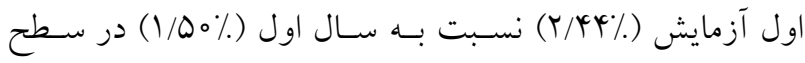

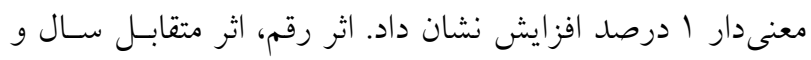

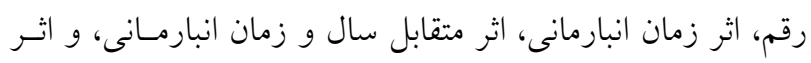

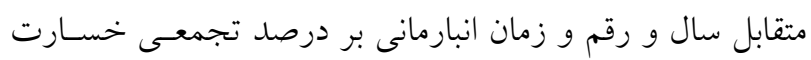
لهيدگى سوخ در سطح احتمال 1\% درصد معنى دار بود (جــدول

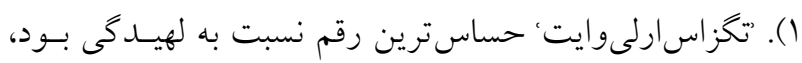

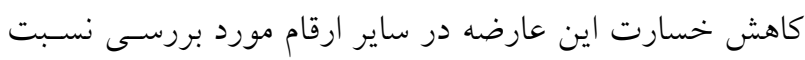

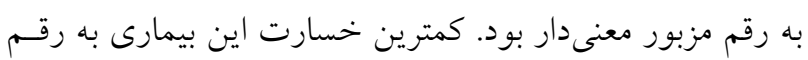

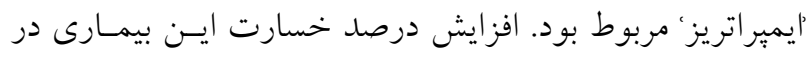

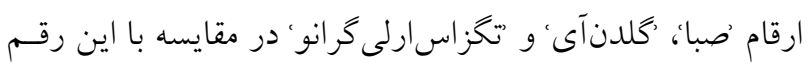

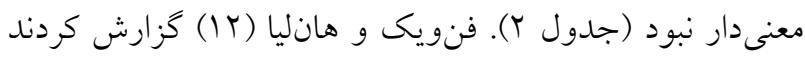

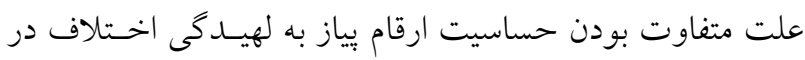

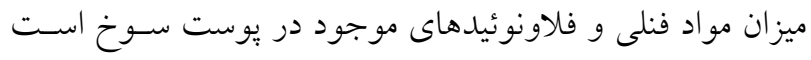
و بهدليل اينكه يوست ارقام قرمز رنخ حاوى مفــدار بيشـترى از اين مواد هستند نسبت به اين بيمارى مقاومترند. ابى و همكاران

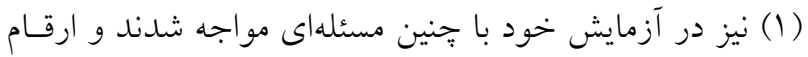

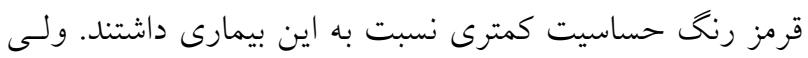


جوانـهزنسى آغـاز شـــ (جـــول 9). ايـن نتـايج بـا كزارشـات يروتويولوس ( (Y) و بروستر (V) كـه بيـان كردنــد مــدت زمـان دوره خواب در ارقام مختلف متفاوت اسـت مطابقـت دارد. اثـر زمان انبارمانى بر درصد جوانهزنى ماهيانسه در سـطح احتمـال يك معنى دار بود. بعد از شكسته شدن خواب و با كذشت زمـان بهعلت كاهش دما و مساعد شدن دما براى جوانه زنسى، درصـد جوانهزنى در هر ماه نسبت به ماه قبـل افـزايش و در مـاه هفـتم (آذر ماه) به حداكثر خود رسيد (جدول ه). علت كاهش درصـد جوانهزنى در ماه هشتم (دى ماه) نسبت به ماه هفتم، علسىرغـم

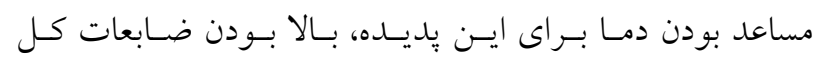

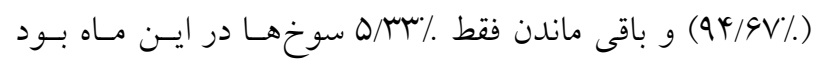

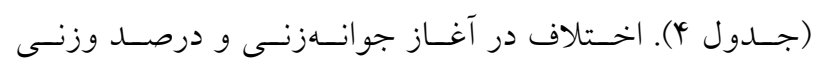
جوانهزنى در دوره انبارمانى در ارقام مورد مطالعه سبب شـــ تـا

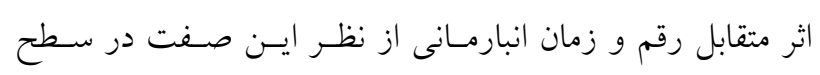
احتمال ا درصد معنىدار شود (جدول (). در ينج ماه اول بعـد "ندان از شروع انبارمانى حداكثر درصد وزنى سوخهاى جوانـهزده بـه رقم نيريماورا' مربوط بود (جدول 9). كاهش سـوخهـاى جوانسه زده در رقم 'سييدان' در مقايسه با اين رقم معنى دار نبود(جــدول

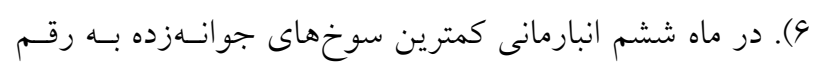
'يكس بيى رد' تعلق داشت. افزايش درصد جوانسهزنسى در سـاير ارقام مورد بررسى نسبت به رقم مزبور معنسى دار بـود (جــدول

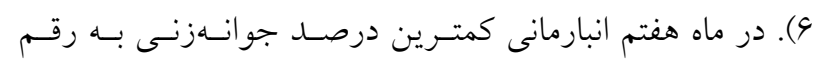

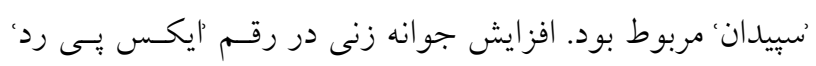

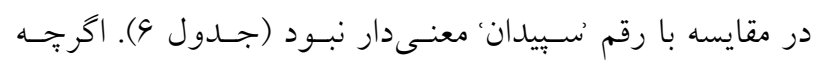
كمترين درصد جوانهزنى در اين ماه به رقم 'سبيدان' مربوط بـود ولى بايستى توجه كرد كه دليل اين موضوع طولانى بـودن دوره خواب اين رقم نيست، بلكه علت آن بالا بودن ميـزان ضـايعات سوخ، تا ماه ششم انبارمانى در اين رفم بود بهطورى كه تا بايـان

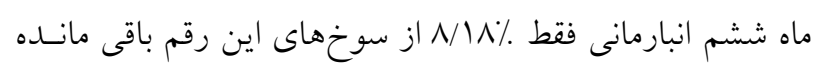
بودند كه همكى آنها در ماه هفتم جوانه زدند. در صورتى كه در

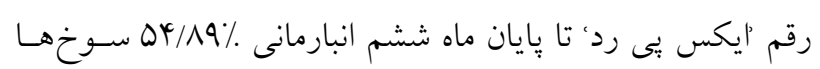

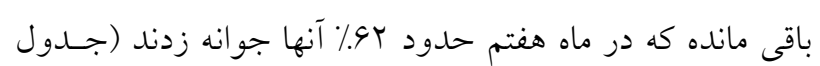

جوانهزنى تجمعسى در سـطح احتمـال ا درصـد معنسىدار بـود (جدول () و ميزان جوانهزنى در سال دوم آزمـايش در مقايسـهـ با سال اول افزايش معنىدارى نشان داد. جوانهزنى عامل مهم از بين رفتن سوخها در اوايل دوره انبارمانى نبود بهطـورى كـهـ در

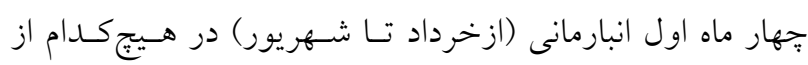
ارقام، سوخها جوانه نزدند (جدول گ). عدم جوانه زنى سوخ در

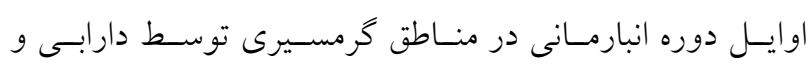
صالحى (9) نيز گزارش شده است. يكى از علل عدم جوانهزنسى

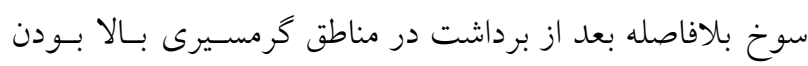

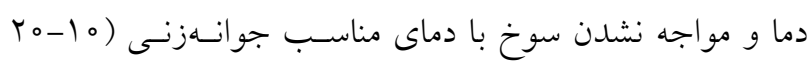
درجه سلسيوس) است. يُروتويولوس و همكاران (Iان) خـزارش نمودند كه مهمترين عامل براى شروع جوانهزنسى سـوخ، دمـاى انبار است و دماى بالا عامل بازدارنده ايسن فراينـــ اسـت. يـو و و

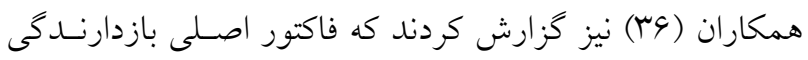

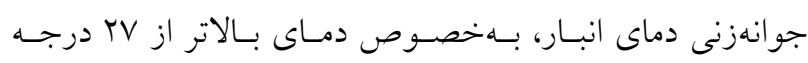
سلسيوس است كه سبب القاء گرمـا خفتخى در سـوخ خواهـــ

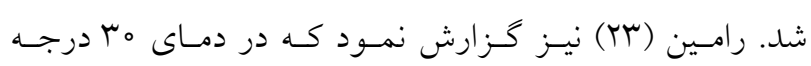
سلسيوس سوخها تا 9 ماه بعد از شروع انبارمانى جوانه نزدهاند. علاوه بر اين محققين زيادى از جمله تـوكر و همكــاران (سب) و

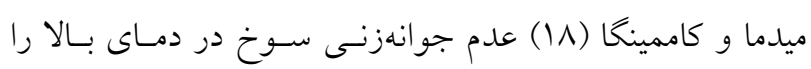

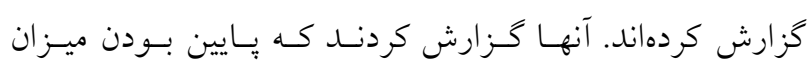
سيتوكينين سوخ در دماى مب درجه سلسيوس يكى از علل عدم

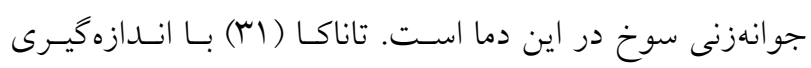
مداوم سرعت تنفس، ارتباط بين خواب سوخ و سـرعت تـنفس

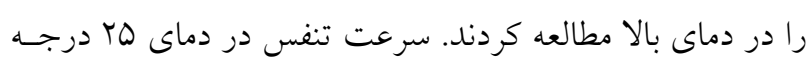
سلسيوس در مقايسه با دماى ها درجه سلسيوس كاهش يافـت. اين محققين نتيجه كيرى كردنـــ كـهـ كـاهش سـرعت تـنفس در دماى هr درجه سلسيوس ناشى از خواب القاء شده توسط گرما

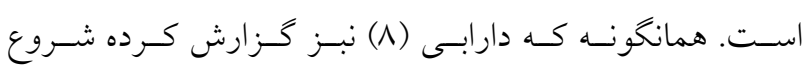
جوانهزنسى در ارقـام مـورد مطالعـه همزمـان نبـود، و در ارقـام

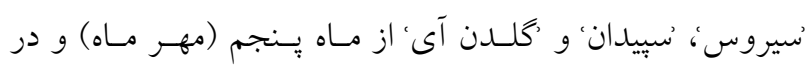
سـايرارقام مــورد بررسـى از مـاه ششــم انبارمــانى (آبـان مــاه) 
يوسسيدكى خاكسـترى، كـاهش معنسى دارى لهيـدكى و كـاهش

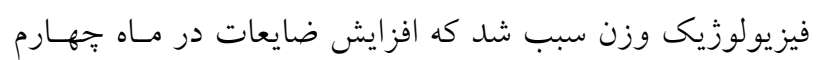

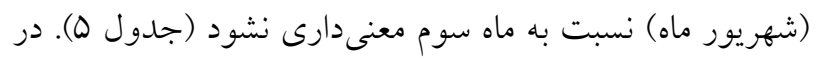

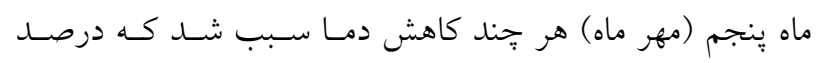

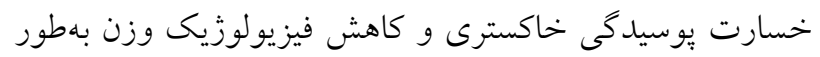

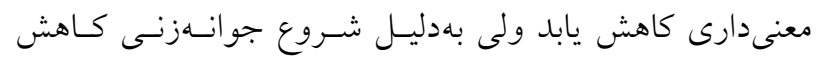

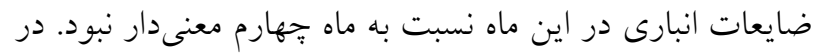

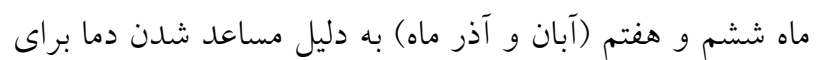
جوانهزنى سوخها، ميزان ضايعات انبارى در هر ماه نسبت به ماه

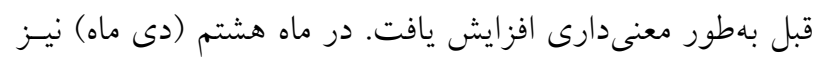

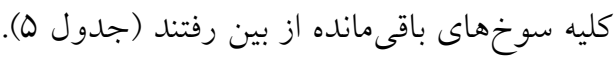
روند تغييرات ضايعات تجمعى در دوره انبارمسانى در ارقـام

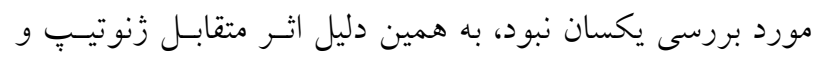

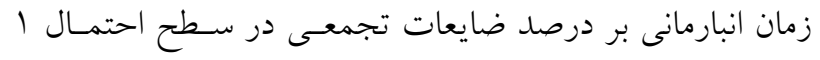

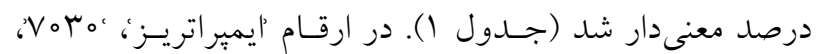

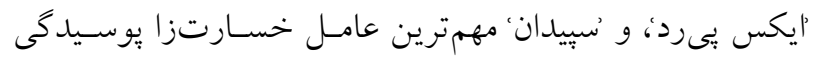

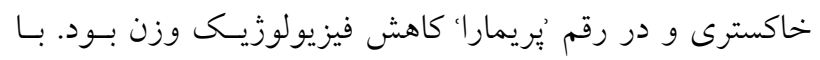

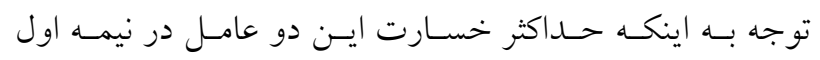

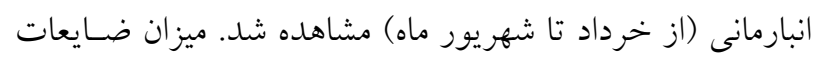

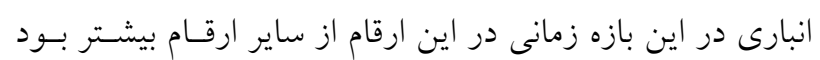

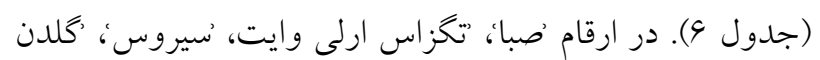

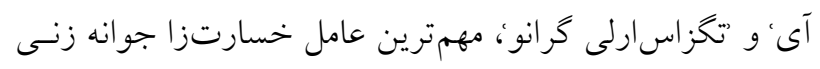
بود كه حداكثر خسارت آن در ماه ششم و هفتم انبارمانى (آبـان

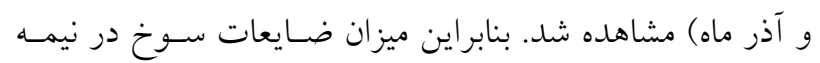

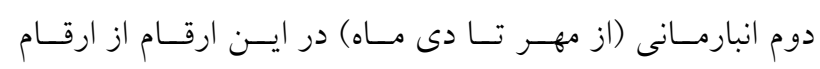

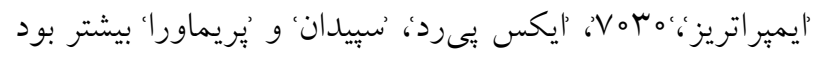

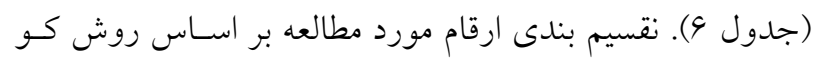

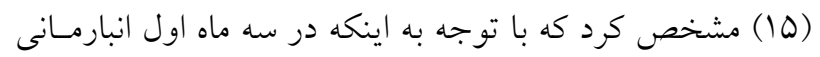

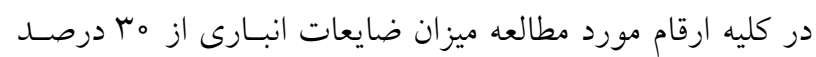

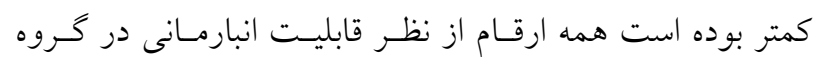

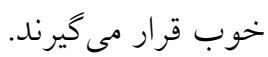

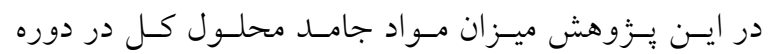

9). با توجه به اينكه در ماه هشتم كليه سـوخهـا در همــه ارقـام

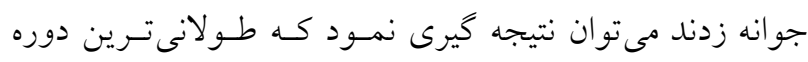

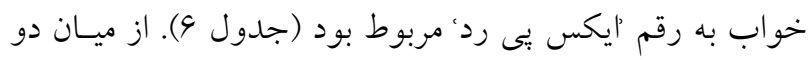

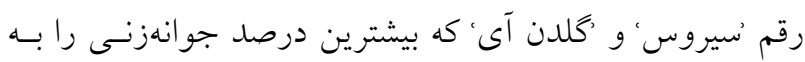
خود اختصاص داده و از نظر اين صفت اختلاف معنسى دارى بـا

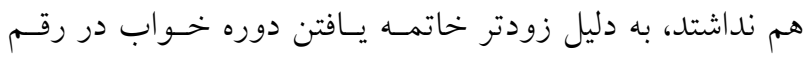

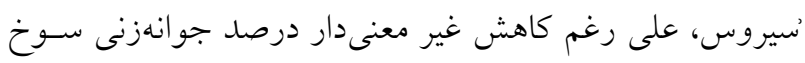

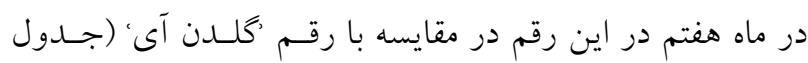

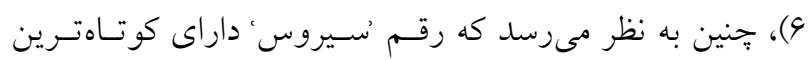

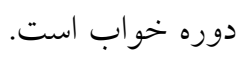
ارزيابى درصد تجمعى ضايعات كل مشـخص كـرد كـه اثـر سال بر اين صـفت در سطح احتمـال ا درصــ معنسى دار بـود.

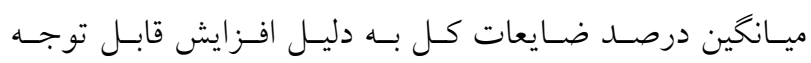

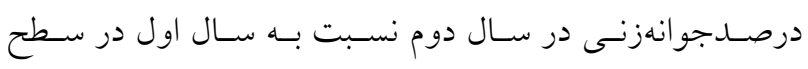

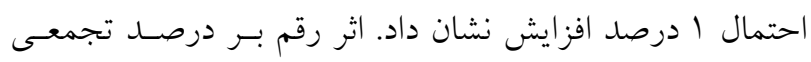
ضايعات كل در سطح احتمال ( درصد معنى دار شد (جدول (1).

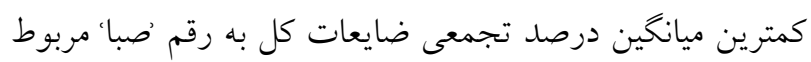

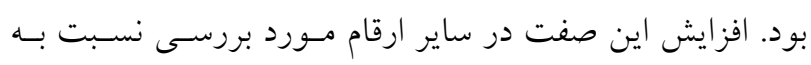

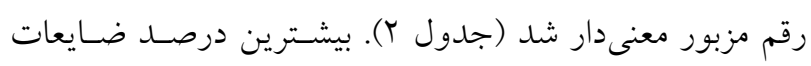

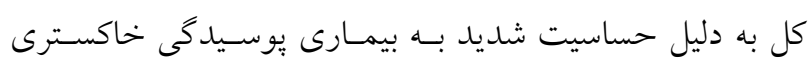

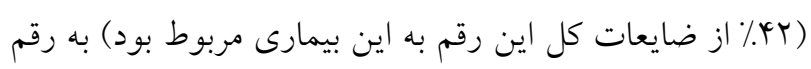

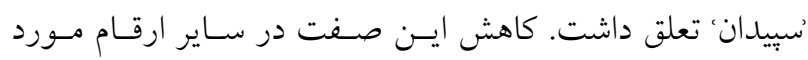

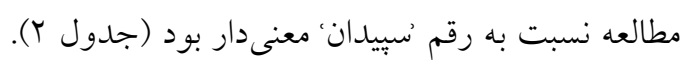

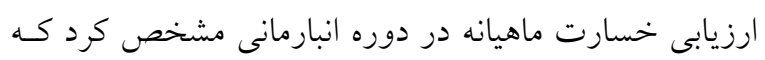

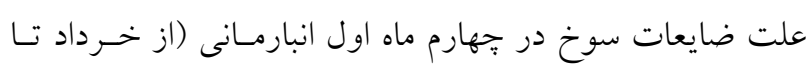

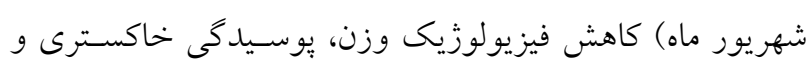

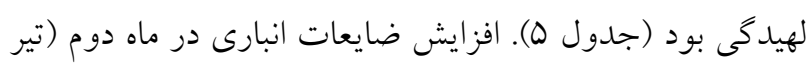

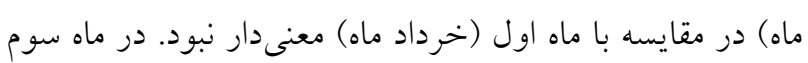

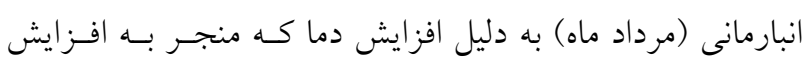
معنى دار خسارت بوسيدكى خاكسترى شد ضايعات كل بهطيور

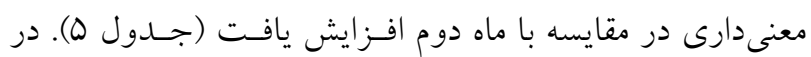

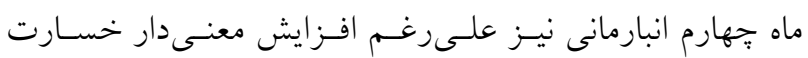




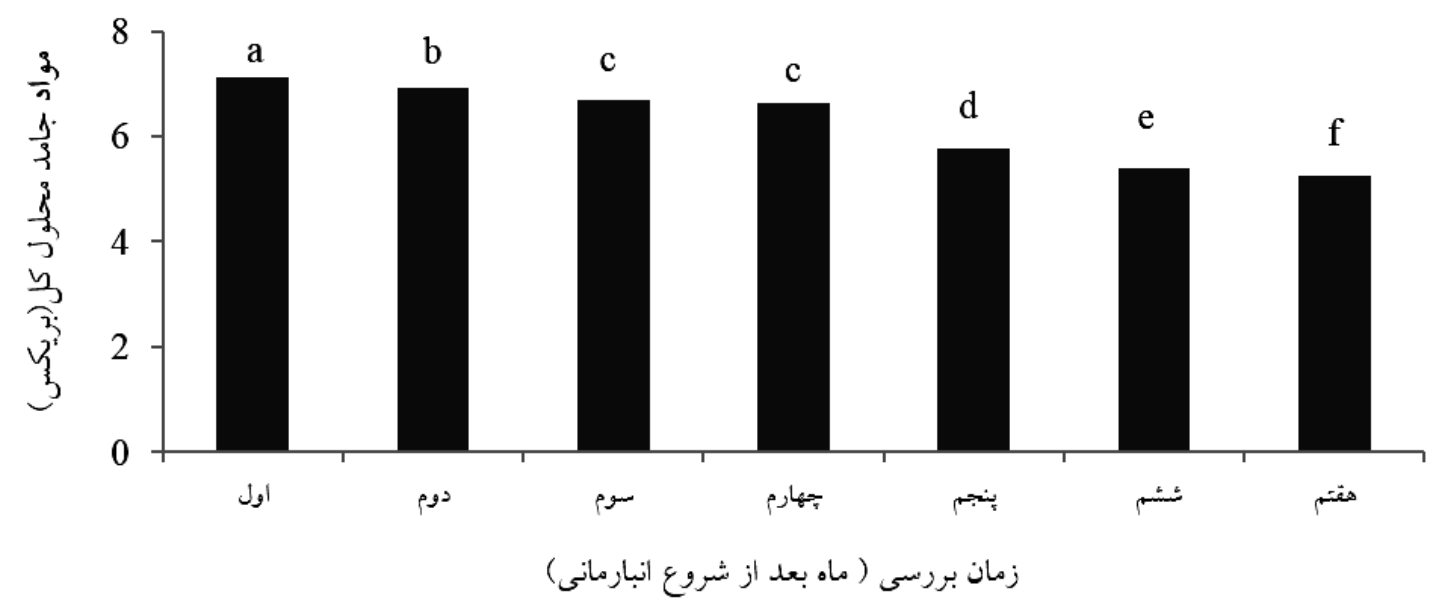

$$
\begin{aligned}
& \text { شكل ا. مقايسه ميانگينهای ماهيانه مواد جامد محلول كل در هنگام انبارمانى. ميانخينهاى هر ستون كه حداقل در يك حرف مشترى } \\
& \text { هستند از نظر آمارى اختلاف معنىدارى در سطح احتمال ينج درصد ندارند. }
\end{aligned}
$$

$$
\begin{aligned}
& \text { توسط سوهانى و همكاران (Y9) نيز گزارش شده است. } \\
& \text { نتايج اين يُزوهش مشخص كـرد كـه در ميـان ارقـام مـورد } \\
& \text { مطالعه كمترين كاهش وزن سوخ به رقم 'صبا' اختصـاص يافت } \\
& \text { (جدول r). رقم 'سيبدان' حساسترين رقم نسبت بـه يوسـيدگى }
\end{aligned}
$$

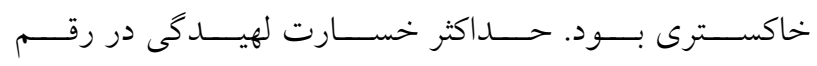

$$
\begin{aligned}
& \text { 'تخزاس ارلى وايت' مشـاهده شـــ (جــدول Y). بيشـترين درصـد } \\
& \text { جوانهزنى به رقم 'سـيروس' تعلـق داشـت (جــدول Y). درصـد }
\end{aligned}
$$

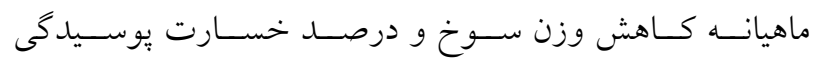

$$
\begin{aligned}
& \text { خاكسترى و لهيدگى با كذشت زمان كمتر شد. جوانهزنى سـوخ }
\end{aligned}
$$

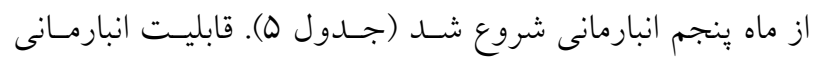

$$
\begin{aligned}
& \text { رقم 'صبا' بهطور معنىدارى بر ساير ارقام برتر بود (جدول r). }
\end{aligned}
$$

$$
\begin{aligned}
& \text { انبارمانى در سال دوم مطالعه شد (لازم به ذكر است بـا توجـهـ بـــ } \\
& \text { اينكه در دوره انبارمانى فقط مواد جامــ محلـول كـل سـوخهـاى } \\
& \text { سالم اندازه گيرى شد و در ماه هشتم كليـه سـوخهــا از بـين رفتـهـ } \\
& \text { بودند اندازهيرى ايـن صـفت، در هفـت مـاه انجـام گرفـت). بـا } \\
& \text { كذشت زمان انبارمانى بهدليل مصرف كربوهيـدراتهــا بـهـعنـوان } \\
& \text { سوبسترا در يديده تنفس، درصد مواد جامــ محلـول كـل سـوخ } \\
& \text { كاهش يافت (شكل (1). دليل كاهش قابـل توجسه ايسن صـفت در } \\
& \text { اواخر دوره انبارمانى رامىتوان جنـين توجيـه كـرد كـهـ در بايسان } \\
& \text { دوره خواب و به هنخام جوانهزنى، ساكارز تبديل به اسيدهاى آلى } \\
& \text { شده و اين اسيدها به جوانههاى در حال رشــد منتقـل مسىشـوند }
\end{aligned}
$$

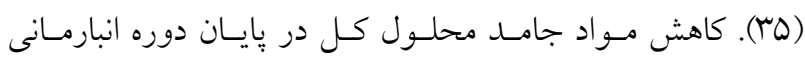

منابع مورد استفاده

1. Abbey, L., O.A. Danquah R. A. L. Kanton and N.S. Olympio. 2000. Characteristics and storage performance of eight onion cultivars. Ghana Journal Science 40: 9-13.

2. Anonymus. 2018. Agricultural statistics, first volume-field crop, 2015-16. Ministry of Jihad-e- Agriculture, Programing and Economic Deputy, Statistics and Information Technology Office. pp. 117. (In Farsi).

3. Ahsanuzzaman, M., M.M. Sarker, R. Hasan, A. Muqit and M. A. U. Doullah. 2017. Assesment of weghit loss of onion in storage due to fungi. Journal of Sylhet Agrilculture University 4(1): 95-100

4. Benkeblia, N., S. Onodera and N. Shiomi. 2005. Variation in 1-fructo-exohydrolase (1-FEH) and ikestosehydrolysing (1-KH) activities and fructo-oligosaccharide (FOS) status in onion bulbs. Influence of temperature and storage time. Journal of the Science of Food and Agriculture 85: 227-334.

5. Biswas, S.K., A. Khair, P.K. Sarkar and M.S. Alom. 2010. Yield and storability of onion (Allium cepa L.) as affected by varying levels of irrigation. Bangladesh Journal of Agriculture Research 321 (5): 247-255.

6. Bosekeng, B. 2012. Response of onion (Allium cepa L.) to sowing date and plant population. M. S. Thesis. Faculty of 
Natural and Agricultural Science Univercity of Free State, Bloemfontein, South Africa.

7. Brewster, J.L. 2008. Onions and other vegetable alliums. (2th ed.). CABI International. Wallingford, UK.

8. Darabi, A. 2018. Storability evaluation of short day onion populations and cultivars in non-controlled storage. Iranian Journal of Horticultural Science 49(1): 105-116. (In Farsi).

9. Darabi, A. and R. Salehi. 2014. Comparison of quantitative and qualitative characteristics and storability of onion populations. Agricultural Crop Management (Journal of Agriculture) 16 (3): 531-543. (In Farsi).

10. El-Nagerabi, S.A.F. and A.H.M. Ahmed. 2003. Storability of onion bulbs contaminated by Aspergillus niger mold. Phytoparasitica 31 (5): 515-523.

11. Eshel, D., P. Tepper-Bamnolker, Y. Vinokur, I. Saad and Y. Zutahy. 2014. Fast-curing: a method to improve postharvest quality of onions in hot climate harvest. Postharvest Biology and Technology 88: 34-39.

12. Fenwick, G.R. and B. Hanleya. 1990. Chernical cornposition. In: H.D. Rabinowith and J.L. Brewster (eds), Onions and Allied Crops, Vol. 3. pp. 17-31. Boca Raton: CRC Press.

13. Kamal, N., A. Saxena, R.O.L. Steiner and C.S. Cramer. 2012. Screening of new mexico autumn-sown onions for black mold disease. HortTechnology 22(5):720-723.

14. Khalifa, M.M.A., N.A. Mahmoud and N.M. Abou-Zeid. 2016. Management of onion bulb rots during storage using pre- and post- harvest control treatments. Egyptian Journal of Phytopathology 44(2): 1-16.

15 Ko, S.S. 2001. Identification of good storability in short-day onion and its mechanism of resistance to Aspergillus niger. Ph.D. Thesis. Natl. Chung Hsing University, Taichung, Taiwan, Republic of China

16. Ko, S.S., J.W. Huang, J.F.Wang, S.Shanmuugasundaram and W.N. Chang. 2002. Evaluation of onion cultivars for resistance to Aspergillus niger, the causal agent of black mold. Journal of American Society for Horticultural Science 127(4): 697-702.

17. Kumar, S., M. Imtiyaz, and A. Kumar. 2007. Effect of differential soil moisture and nutrient regimes on postharvest attributes of onion (Allium cepa L.). Scientia Horticulturae 112: 121-129.

18. Miedema, P. and G.C. Kamminga. 1994. Bulb dormancy in onion. II. The role of cytokinins in high- temperature imposed sprout inhibition. Journal of Horticultural Science 64: 41-45.

19. Parkash, D., B.N. Singh and G. Upadhyay. 2007. Antioxidant and free scavenging activities of phenols from onion (Allium cepa L.). Food Chemistry 102 (40): 1389-1393.

20. Petropoulos S.A., A. Fernandesb, L. Barrosb, J.C.M. Barreirab, I.C.F.R. Ferreirab and G. Ntatsi. 2016. Long-term storage effect on chemical composition, nutritional value and quality of Greek onion landrace "Vatikiotiko" Food Chemistry 201: 168-176.

21. Petropoulos, S.A., G. Ntatsi and I. C. F. R. Ferreira. 2017. Long-term storage of onion and the factors that affect its quality: A critical review. Food Reviews International 33 (1): 62-83.

22. Rajapakes, R.G.A. S. and E.R.S.P. Edirimanna. 2002. Management of bulb rot of big onion (Allium cepa L.) during storage using fungicides. Anna/s of the Sri Lanka Department Agriculture 4:319-326.

23. Ramin, A.A. 1999. Storage potential of bulb onion (Allium cepa L.) under high temperatures. Journal of Horticultural Science \& Biotechnology 74 (2): 181-186.

24. Rostam Forudi, B. 2006. Study on quantitative and qualitative characteristics of onion cultivars and determination of the relation between some characters and storability. Seed and Plant 22 (1): 67-86. (In Farsi).

25. Saranya R., V.B. Anadani, L.F. Akbari and M. Vanthana. 2017. Management of black mold of onion [Aspergillus niger (Van Teigh)] by using various fungicides. International Journal of Current Microbiology and Applied Sciences 6 (3): 1621-1627

26. Schroeder, B.K. and L.J. Du Tiot. 2010. Effect of postharvest onion curing parameters on entrobactor bulb decay in storage. Plant Disease 94: 1425-2430.

27. Shah Murad, S., K. Khalid Niaz, A. Ali and A. Aslam. 2018. Ginger and onion: new and novel considerations. Pharmacy and Pharmacology International Journal 6 (1) 200: 49- 52.

28. Sharma, K., A.D. Assefa, E.Y. Ko, E.T. Lee, S.W. Park .2015. Quantitative analysis of flavonoids, sugars, henylalanine and tryptophan in onion scales during storage under ambient conditions. Journal of Food Science and Technology 52: 2157-2165.

29. Sohany, M., K. Uddin Sarker and S. Mahomud. 2016. Physiological changes in red onion bulbs at different storage temperature. World Journal of Engineering and Technology 4: 261-266.

30. Soomro, S.A., K.A. Ibupoto, N.M. Soomro and L.A. Jamali1. 2016. Effect of storage method on the quality of onion bulbs. Pakistan Journal of Agriculture, Agricultural Engineering and Veterinary Sciences 32 (2): $221-228$.

31. Tanaka, K. 1991. Studies on the black mold disease of onion bulb caused by Aspergillus niger Van Tieghem. Bulletin of Agriculture Faculty Saga University 70: 1-54.

32. Tripathi, P.C., V. Sankar, V.M. Mahajan and K.E. Lawande. 2011. Response of gamma irradiation on post harvest losses in some onion varieties. Indian Journal of Horticulture 68 (4): 556-560. 
33. Tucker, W.G., G.R. Stowand and C.M. Ward. 1977. The high temperature storage of onion in United Kingdom. Acta Horticulturae 62: 181-189.

34. Tysoni, J.L. and R.A. Fullerton. 2004. Effect of soil borne inoculum on incidence of onion black mould (Aspergillus niger). New Zealand Plant Protection 57: 138-141.

35. Yasin, H. and G. Bufler. 2007. Dormancy and sprouting of onion (Allium cepa L.) bulbs. I. Changes in carbohydrate metabolism. The Journal of Horticultural Science and Biotechnology 82: 89-96.

36. Yoo, K.S., C.R. Andersen and L.M. Pike. 1997. Internal CO2 concentrations in onion bulbs at different storage temperatures and in response to sealing of the neck and base. Postharvest Biology and Technology 12: 157-163. 


\title{
Comparative Postharvest Losses of Short Day Onion (Allium cepa L.) Cultivars in Uncontrolled Storage Conditions
}

\author{
A. Darabi ${ }^{1^{*}}$ \\ (Received: August 10-2019; Accepted: September 07-2020)
}

\begin{abstract}
This research was conducted at the Behbahan Agriculture Research Station, Behbahan, south-west of Iran, for two years from 2016 to 2018 to study the postharvest losses of short-day onion cultivars in uncontrolled storage conditions (no heating, cooling and ventilation systems). Seeds were sown in nursery in early October and seedling transplanted at 2-3 leaf stage. Bulbs were harvested when $50-80 \%$ of foliage had dried and fallen and prepared for the experiment in both years. In the 1 st year of experiment, the average of daily storage temperature and relative humidity ranged from 14.5 to $40.5^{\circ} \mathrm{C}$ and 27 to $60 \%$, respectively. The average of daily storage temperature and relative humidity varied from 15 to $38{ }^{\circ} \mathrm{C}$ and 30 to $71 \%$, respectively, in the 2 nd year of experiment. This research was performed using a split plot experiment based on a randomized complete block design encompassing 80 treatments with 4 replications. Main plot consisted of 10 cultivars ('Seba', 'Texas Early White', 'Imperateriz', 'Siroos', '7030', 'X P red', 'Sapidan', 'Golden I', 'Texas Early Grano' and 'Primavera') and bulbs evaluation in storage at eight times (one months after start of storage with one month interval) was considered as sub plot. The monthly bulb weight losses percentage decreased with time. The minimum weight loss $(9.56 \%)$ was recorded in 'Seba vultivar. The damage of black mold increased until the fourth month of storage and then decreased. 'Sapidan' was the most sensitive cultivar to damage of black mold (23.23\%). The highest percentage of bulb rotting (29.65\%) was observed in 'Texas Early White' cultivar. Bulb sprouting was observed from the fifth month of storage and the highest bulb sprouting (19.88\%) belonged to 'Siroos' cultivar. Results were suggestive of difference in storability among cultivars, the maximum and minimum storability being recorded in 'Seba' and 'Sapidan', cultivars, respectively.
\end{abstract}

Keywords: Black mold, Bulb rotting, Bulb sprouting, Losses after harvest, Physiological bulb weight losses

1. Associate Professor, Seed and Plant Research Improvement Department, Khuzestan Agricultural and Natural Resources Research and Education Center, AREEO, Ahwaz, Iran

*: Corresponding Author, Email: darabi6872@yahoo.com 